\title{
IMPLICACIONES DE LA IMPLANTACIÓN DE LA LEY DE RACIONALIDAD Y SOSTENIBILIDAD DE LAS ADMINISTRACIONES LOCALES (LEY 27/2013) EN LAS ADMINISTRACIONES LOCALES DE LA COMUNITAT VALENCIANA
}

\author{
Joan Noguera Tur \\ Profesor Titular Departamento de Geografía \\ Director del Instituto Interuniversitario de Desarrollo Local \\ Universidad de Valencia \\ Joan.noguera@uv.es \\ Giuseppe Scardaccione, gius.scarda@gmail.com \\ Estefanía Gascó Martínez, esgasma@gmail.com \\ Mar Riera Spiegelhalder, mar.riera@uv.es \\ Héctor del Alcázar Indarte, hector.alcazar@uv.es \\ Personal Investigador \\ Institut Interuniversitari de Desenvolupament Local \\ Universitat de València
}

\section{RESUMEN}

En menos de un cuarto de siglo el texto de la Ley Reguladora de las Bases del Régimen Local (LRBRL) ha sido modificado doce veces, con cambios que afectan a 41 de los 120 artículos, al tiempo que se han añadido 37 nuevos artículos y disposiciones adicionales. La última de estas modificaciones, con profundas implicaciones en la forma de operar de las administraciones locales, ha levantado suspicacias e incertidumbres sobre el papel de los gobiernos locales. Tras su publicación en el BOE, la Ley 27/2013 del 27 de diciembre de racionalización y sostenibilidad de la administración local (LRSAL), ha generado numerosas controversias entre los profesionales del municipalismo. Es desde este sentir que se ha emprendido la realización de un trabajo de análisis que permita conocer, a partir del análisis documental y de la evidencia empírica, las opiniones dominantes y emergentes sobre esta nueva reforma y la situación en la que queda la gobernanza de las administraciones locales como consecuencia de la implantación de la LRSAL.

PALABRAS CLAVES: Sector público, localismo, gobernanza, competencias impropias, duplicidades, racionalidad y sostenibilidad financiera 


\title{
IMPLICATIONS OF THE IMPLEMENTATION OF THE LAW ON RATIONALITY AND SUSTAINABILITY OF LOCAL AUTHORITIES (LAW 27/2013) IN THE LOCAL ADMINISTRATIONS OF THE COMUNITAT VALENCIANA
}

\begin{abstract}
In less than a quarter century, the text of the Law regulating local administrations (LRBRL) has been amended a dozen times, introducing changes in 41 of the 120 articles, while 37 new articles and additional provisions have been added. The last of these changes, with profound implications for the way local government operates, has raised suspicions and doubts regarding the immediate future role of local governments. After its publication in the Official State Gazette (BOE), the Law 27/2013 of December $27^{\text {th }}$ of Rationalization and Sustainability of Local Administrations (LRSAL) has generated much controversy among municipal professionals. It is in this sense that the authors have undertaken the realization of an analysis to find out, from relevant documents and empirical evidence, the emerging views on the reform and the situation of the governance of local administrations as a result of the implementation of the LRSAL.
\end{abstract}

KEYWORDS: Public sector, localism, governance, improper powers, duplicities, financial rationality and sustainability

Reseña biográfica: El Grupo LOCSUS se centra en el análisis de los elementos y variables que intervienen en el desarrollo sostenible de los territorios y las sociedades, el desarrollo de metodologías de planificación estratégica, el estudio de los procesos que intervienen en el enfoque local del desarrollo, el seguimiento y evaluación de políticas públicas (sistemas de indicadores), y la coordinación y la participación en los procesos de desarrollo local. Además, el Grupo LOCSUS atiende al análisis de los procesos políticos y sociales en tanto que relacionados con el desarrollo sostenible de los pueblos. Sus principales líneas de investigación incluyen el desarrollo local (estudios sobre el diseño y aplicación efectiva de políticas que se adapten a las necesidades locales) y el desarrollo sostenible y planificación urbana (pautas e instrumentos de planificación territorial destinados a facilitar la incorporación del concepto de sostenibilidad en el ámbito local, a través de una serie de recomendaciones que permitan alcanzar una mayor cohesión social, un medio ambiente urbano de mayor calidad y un desarrollo económico perdurable).

\section{Planteamiento}

La Ley Reguladora de las Bases del Régimen Local (LRBRL) es el principal instrumento normativo que regula la acción de las administraciones locales en España. En menos de un cuarto de siglo, el texto de esta ley fundamental ha sido modificado una docena de veces, con cambios que afectan a 41 de sus 120 artículos, al tiempo que se han añadido 37 nuevos artículos y disposiciones adicionales. La última de estas 
modificaciones es también la más profunda, y plantea implicaciones esenciales en la forma de operar de las administraciones locales en un contexto en el que estos niveles de gobierno se han convertido, en la práctica, en verdaderos garantes de algunos de los principales derechos reconocidos por la constitución. La reforma, guiada básicamente por el principio de equilibrio presupuestario, ha levantado incertidumbres sobre el modelo vigente de municipalismo en España y ha puesto en cuestión el papel de los gobiernos locales, si llega a implantarse en toda su extensión.

Tras su publicación en el BOE, bajo el nombre de Ley 27/2013 del 27 de diciembre de Racionalización y Sostenibilidad de la Administración Local (LRSAL), la última reforma de la LRBRL ha generado numerosas dudas, debates y controversias entre los profesionales del municipalismo, y una sensación de inseguridad y paralización que afecta a los ayuntamientos y a otras administraciones locales en uno de los periodos más delicados de la historia reciente. La Ley supone una reorganización del modelo municipal y autonómico en que desaparecen las entidades locales supramunicipales, se delimitan las competencias en función del número de habitantes, y se dota de mayor protagonismo a órganos intermedios como las cuestionadas diputaciones.

En este contexto se ha emprendido la realización de un trabajo de análisis cuya finalidad es conocer, a partir de la revisión documental y la evidencia empírica, las opiniones dominantes y emergentes sobre esta nueva reforma, y la situación en que queda la gobernanza de las administraciones locales como consecuencia de la implantación de la LRSAL.

La investigación se fundamenta varias hipótesis. La Hipótesis 1 (H1) afirma que la LRSAL responde a un modelo clásico de burocracia que fomenta una intervención estatal en detrimento de la autogestión local/municipal. Se trata de un proyecto que parte de una doctrina eminentemente centralizadora que no se corresponde bien con la naturaleza autónoma de los municipios a lo largo de la historia española, reforzada desde la transición a la democracia. A pesar de esta valoración negativa, la Hipótesis 2 $(\mathrm{H} 2)$ afirma que la Ley contiene una aspiración positiva pero mal desarrollada con respecto a la realidad de las administraciones locales. Su revisión de las disposiciones relativas al estatuto jurídico de la Administración Local es interesante cuando trata de evitar las duplicidades en el manejo de competencias. Pero, aunque trate de estabilizar los presupuestos y lograr una mayor eficiencia en el uso de los recursos públicos, no tiene en cuenta las necesidades de los municipios de proveer a sus ciudadanos de un buen número de bienes y servicios que, desde un gobierno más centralizado, resultan menos eficaces. Así, la segunda hipótesis de trabajo es que la LRSAL es una ley de racionalización del gasto público y no tanto de sostenibilidad. Por último, la tercera hipótesis (H3) afirma que la LRSAL se apropia, mediante su reglamento, de las potestades constitucionales de las entidades locales referidas en los artículos 137, 140 a 142 CE.

Vistas las hipótesis, el objetivo radica en plantear el impacto derivado de la implantación de la LRSAL en las entidades locales. Se trata de configurar un mapa específico de datos mediante la revisión de la literatura relevante y el conjunto de reflexiones del personal administrativo y político de entidades locales, y su rol dentro del régimen local. Se pretende alcanzar una conclusión satisfactoria que nos permita evaluar el impacto real de la LRSAL en su intento de "apaciguar" las asimetrías y 
sobredimensionamiento de las Haciendas Locales, más las polarizaciones municipales en materia de duplicidades en competencias específicas y delegadas.

Al mismo tiempo, y en desarrollo de este objetico general, se plantean algunos objetivos específicos: en primer lugar, determinar el contexto político y legislativo de las AALL previo a la implementación de la LRSAL; en segundo lugar, comparar el modelo administrativo de la Ley de Bases del Régimen Local del 1985 -y sus consecuentes reformas- con el actual modelo de la LRSAL de 2013; en tercer lugar, conocer la repercusión de la implantación de la LRSAL en base a la experiencia del personal del sector público local; en cuarto lugar, conocer y comparar las opiniones del personal del sector público para construir un cuadro de reflexión del nuevo modelo municipal (y de la administración periférica sujeta a reforma); por último, proponer medidas oportunas para implementar un modelo de desarrollo local más realista con la nueva realidad 'localista' en base a los principios de nuestro Estado de las Autonomías.

\section{Enfoque metodológico}

Durante el periodo que abarca desde octubre de 2013 a abril de 2014, los autores llevaron a cabo dos jornadas de trabajo destinadas a analizar el contenido de la LRSAL y su impacto en el funcionamiento de las administraciones locales. Ambas jornadas fueron multitudinarias y el público participante estuvo constituido principalmente por secretarios, interventores y tesoreros de ayuntamientos y mancomunidades, agentes de desarrollo local y comercial, y, aunque en un número menor, concejales y asesores políticos. Ambos encuentros permitieron identificar los principales retos que la reforma de la Ley marca a futuro, al tiempo que se aprovechó para lanzar una encuesta tanto a los asistentes como a otros actores involucrados y con interés en la reforma de la Ley.

La información extraída de las discusiones y de la encuesta aporta un valor añadido al estado de la cuestión dada la inexistencia de información previa sobre el nuevo modelo que propone la LRSAL. De hecho, uno de los principales objetivos es dar respuesta a las preguntas que, de modo general, suscitó el Anteproyecto de Ley en octubre del 2013: en primer lugar, si se aplica de manera eficiente, la LRSAL podría llegar a ser la vía para eliminar duplicidades y conseguir la idea de "una administración, una competencia", pero la coordinación entre administraciones es una asignatura largamente pendiente; en segundo lugar, en qué medida el refuerzo de las entidades provinciales puede contribuir a asegurar el mantenimiento y los estándares de provisión de servicios básicos de interés general, sobre todo en los municipios más pequeños, los que presentan un mayor riesgo de despoblación y desarticulación territorial; en tercer lugar, cuál es el papel potencial de una administración local intermedia como ente capaz de gestionar los servicios de manera más eficiente; ¿qué "aspecto" tiene dicho modelo?; en cuarto lugar, dudas en torno al modelo de delegación de competencias que, en principio, parece interesante ya que obliga a la transferencia de los recursos presupuestarios necesarios, pero deja algunas dudas importantes como la nula capacidad de los ayuntamientos para determinar cuáles son las competencias a transferir en función de la realidad que viven en el día a día o de las necesidades detectadas en la población local, o el modelo de provisión de una determinada competencia que vendrá también "impuesto" desde arriba. ¿Queda 
margen para una verdadera reflexión, planificación y gestión estratégica del desarrollo local en el ámbito de los municipios o agrupaciones municipales? Por último, se han analizado todos los datos obtenidos mediante el instrumento de la encuesta para conseguir una aproximación a las opiniones que la LRSAL ha fomentado entre las entidades locales desde una posición de objetividad. 


\section{El sistema de gobierno local en España y la reforma de 2013}

Según su ordenamiento jurídico, España es un Estado Autonómico unitario descentralizado políticamente, ya que la soberanía recae en el reconocimiento de la existencia de instituciones políticas territoriales con capacidad para autogobernarse en el marco de las competencias trasferidas por el poder central. Así es como lo dispone el artículo 2 o de la CE de 1978, que garantiza el derecho a la autonomía de las nacionalidades y regiones que integran el Estado en base a unos principios básicos de la administración territorial, a saber: autonomía, participación democrática, solidaridad, autonomía financiera, estado unitario y unidad económica.

La Constitución de 1978, en su Capítulo Octavo, determina la organización territorial del Estado mediante el establecimiento de Comunidades Autónomas, provincias y municipios. A pesar de su organización semi-federalista, la Constitución prohíbe la federación de Comunidades Autónomas, pero permite otras formas de organización territorial y administrativa como la comarca, mancomunidad, cabildo, etc. El mapa administrativo actual de España refleja, por un lado, la influencia de la historia y, por otro, los cambios derivados de los contextos y coyunturas socioeconómicas.

El modelo constitucional de descentralización garantiza la necesidad de asentarse sobre "tres pilares": Estado, Comunidades Autónomas y Entes Locales. Cada uno de estos "pilares" cuenta con sustantividad propia. Y éstos, a su vez, se establecen en un modelo de Estado con tres administraciones con personalidad jurídica: la central, la autonómica y la local, sin que ninguna de ellas esté sometida ni subordinada a la otra.

Con el fin de establecer una comunicación eficiente se concretó una red supramunicipal de entidades territoriales que conectan la periferia con la Administración Central, y la AAPP con los Entes Locales. La Administración periférica es un complejo organizativo dependiente de la administración modular para asegurar la presencia en el territorio de la Administración General del Estado a través de las Diputaciones provinciales o Delegaciones de gobierno.

\section{Las Entidades Locales}

La planta municipal existente es heredera de las reformas administrativas establecidas durante el siglo XIX tras la muerte de Fernando VII. La voluntad liberal de las Cortes de Cádiz de 1812 fue un elemento clave a la hora de configurar el modelo municipal propio del Antiguo Régimen, favoreciendo criterios demográficos en detrimento de otros de carácter territorial. Esto produjo la generalización de un mapa municipal constituido según relaciones de convivencia al equiparar el núcleo de población con el municipio en cuanto a asentamiento de población en un territorio sociológicamente preexistente (Morell Ocaña, 1992). De esta idea romántica nace el entramado de Administraciones Públicas que integran la estructura del Estado: las Entidades locales constituyen el escalón territorial inferior al propio Estado y a las CCAA, lo que queda establecido por el artículo 137 de la Constitución del 78.

La evolución histórico-política de España ha conformado una planta municipal formada por 13.000 entidades públicas, de las cuales 8.112 corresponden a ayuntamientos y 61 
a Diputaciones, Consejos y Cabildos con características y población muy diferentes en cuanto a sus necesidades y dimensiones. Cuando se analiza el mapa municipal español se observa su escasa homogeneidad con relación al tamaño y a la distribución territorial del crecimiento. El 90\% de los municipios en España corresponde a unidades administrativas con menos de 5.000 habitantes.

El art. 137 CE destaca que la organización territorial del Estado corresponde a una estructura de gobierno democrático-representativo con una enorme amplitud de fines institucionales, lo cual supone un reconocimiento constitucional a la autonomía de los municipios, sin que queden subordinados al Estado o a la CCAA. Este artículo define la titularidad de facultades de autodeterminación para fijar la forma en que han de satisfacer los fines que les atribuye el ordenamiento jurídico. A este respecto, el Libro Blanco del Gobierno Local afirma que "La autonomía -de garantía constitucionalimplica la necesidad de que todo el territorio nacional se organice en municipios y provincias; el reconocimiento de una esfera de intereses propios y la atribución de competencias de gestión; la auto-selección de sus órganos de gobierno; y la suficiencia económica para el ejercicio de sus competencias (art. 142 CE)" (pag. 25).

Figura 1. Densidad de población por municipios. España 2014

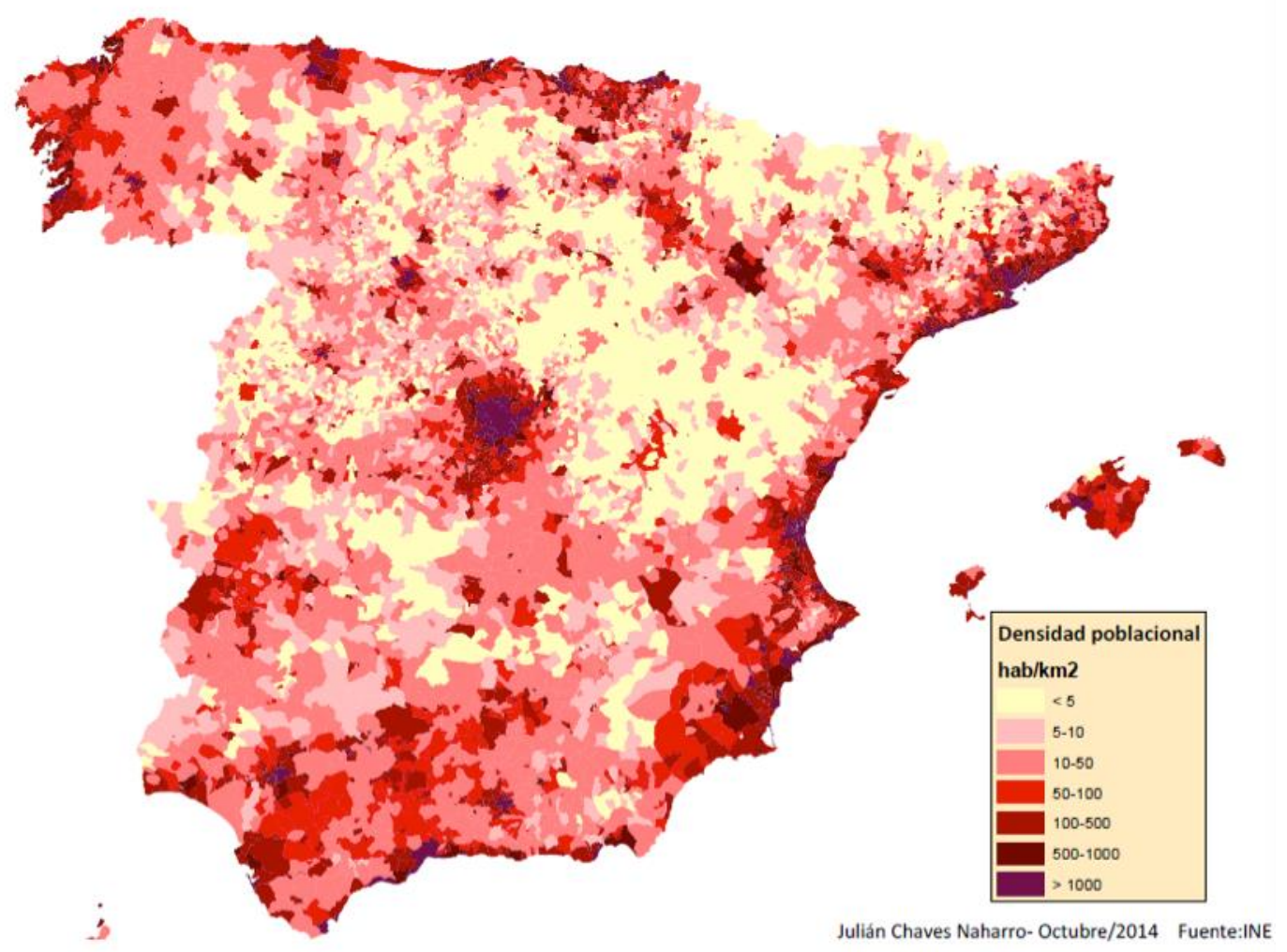

Fuente: ulum.es 
La Administración municipal necesita contemplarse desde una doble perspectiva: la estructural, que analiza los elementos que la integran, y la funcional, centrada en el análisis de sus competencias. La Administración Local aparece regulada en la Ley 30/1992, de 26 de noviembre, del Régimen Jurídico de las Administraciones Públicas y del Procedimiento Administrativo Común. El artículo 2 de la mencionada norma establece que, la Administración Local es una de las administraciones públicas de Administración Regional. La citada ley establece que la Administración General del Estado, las Comunidades Autónomas y las Entidades que integran la Administración Local deberán colaborar y auxiliarse para aquellas ejecuciones de sus actos que hayan de realizarse fuera de sus respectivos ámbitos territoriales de competencias. Esta dotación de auto-organización amplia de las entidades locales, tiene una pluralidad de origen en su regulación organizativa y de actividades, que confluyen con las competencias normativas estatales, autonómicas y propias. La ley de competencias estatales se centraba en la Ley Reguladora de las Bases de Régimen Local 7/1985, de 2 de abril, la cual clasificaba las entidades locales en dos grupos: entidades de régimen común o carácter imperativo (municipios, provincias e islas), y entidades de régimen especial o carácter dispositivo (divisiones sub-municipales, comarcas, áreas metropolitanas y mancomunidades). Su configuración final se presenta como un sistema fragmentado y diversificado en número, heterogeneidad social y de limitada autonomía competencial lo que algunos autores han venido a denominar “inframunicipalismo" (Carrillo, 1991).

\section{Marco Normativo previo a la Ley 27/2013, de 27 de diciembre, LRSAL}

A la hora de resolver el mapa resultante de "inframunicipalismo" en el modelo español de organización territorial debemos conocer los efectos prácticos del imaginario contemplado por la CE de 1978, Título VIII dentro del apartado de la Administración Territorial, en lo correspondiente a la Administración Local (artículos 137, 140 a 142). Se trata de una construcción del régimen local caracterizada por el principio democrático y el principio de autonomía para la gestión de los intereses respectivos. Tras esta base constitucional acaece una expansión legislativa impulsada durante la década de los ochenta que reguló el desarrollo organizativo del Régimen Local en España. A este respecto pueden destacarse las siguientes normas: en primer lugar, la Ley 7/1985 del 2 de abril, reguladora de las Bases del Régimen Local (LBRL); seguidamente, el Real Decreto-legislativo 78/1986 del 18 de abril, texto refundido de las disposiciones legales vigentes en materia del Régimen Local (TRRL); por último, la Ley 38/1988 del 18 de diciembre, reguladora de las Haciendas Locales (LHL).

El marco normativo citado hasta el momento se ha implementado con notable éxito, aunque en los últimos años ha sido objeto de diversas reformas. Las más relevantes son, por un lado, el Pacto Local (Ley 7 y 11/1999) que afectó especialmente al principio de autonomía local, las potestades de los alcaldes, introdujo la cuestión de confianza y entre otros, el reconocimiento de los grupos políticos dentro del funcionamiento ordinario de los municipios. Por otro lado, la Ley 57/2003, que alteró por primera vez la uniformidad municipal histórica de nuestro país, al contemplar un "Régimen específico" para las "grandes ciudades". Más adelante, en 2004, se promulgó un texto refundido de Haciendas Locales. Y en este repaso legislativo destaca la no nata Ley Básica del Gobierno Local, elaborada en 2006 en respuesta a los contenidos del Libro 
Blanco para la Reforma del Régimen Local. Además, y como apéndice de interés, conviene destacar el conjunto de Recomendaciones y Convenios del Consejo de Europa sobre democracia local especificados en la CEAL (Carta Europea de Autonomías Locales), ratificada por el Estado español.

En cuanto al desarrollo legislativo en lo que refiere a las economías municipales, Cuenca (2010) aporta unas interesantes reflexiones sobre la aplicación de la de la norma de 1988 y la de 2004. No se observa una implantación efectiva en la reducción del déficit y la insuficiencia de recursos de las haciendas de las Corporaciones locales. Buena parte de la inversión está constituida por la asunción de los denominados "servicios impropios" que la Ley de Bases de Régimen Local 1985 no logró regular durante sus años de vigencia. En parte, por la postura del Tribunal Constitucional que trastocó -con su Sentencia 214/1989- el diseño del legislador para auto-organizarse municipalmente según concuerdan Parejo (1997), Sosa Wagner (1996) y Cuenca (INAP; 2010).

Al declarar derogado el sistema de fuentes normativas aplicables al régimen local a favor de la CCAA, se han regulado las competencias de un modo compartido y caracterizado por una elevada dependencia de la administración central y autonómica. Esta naturaleza bifronte desplaza al ROM (Reglamento Orgánico Municipal) a la sombra del desarrollo autonómico.

\section{Relación de entidades de la Administración Local: el Principio de Autonomía}

La Administración Local pasa por una importante crisis cuyos factores causales son la interconexión y desplazamiento supralocal de intereses y la escasez de medios financieros determinante para la absorción de competencias desde el Estado y las CCAA. Por ello el tema más polémico, y por el que se enfrentan en la cuestión de definición de competencias municipales de nuestro régimen local es ciertamente difuso, como veremos a continuación. Por una parte, en el Libro Blanco se aboga por un modelo de gestión gerencial, es decir multinivel y descentralizado para una mayor eficiencia en la distribución e implantación de las competencias y órganos complementarios, que doten al gobierno local de una estructura administrativa interna más eficaz en sus necesidades específicas. Se trata de evitar la estandarización de las competencias en todo el territorio nacional. En esta línea podemos ubicar también la Carta Europea de Autonomía local, que aboga por un gobierno que no funcione únicamente como ente gestor, sino que sea re-politizado y que permita la acción ciudadana a través de lo local. Es decir, se trata de una apuesta por una mayor diversidad local y por dar libertad a los municipios a la hora de decidir sus propias necesidades competenciales. Una filosofía ésta que, sin duda, choca frontalmente con la Ley 27/2013, de 27 de diciembre, que propone actuar de un modo más centralizado para evitar asimetrías y sobredimensionamiento en materia de Hacienda Local.

Además de racionalizar el entramado estructural de las Administraciones Locales, se trata de no perder de vista las implicaciones del artículo $137 \mathrm{CE}$, que dota de amplitud institucional a los territorios municipales en la consecución de sus fines a partir de su propia autonomía constitucional. Esto ocurre cuando la LRSAL anima a fusionar municipios de forma "voluntaria" en entidades de régimen especial o de carácter 
imperativo con el fin de recortar en gastos y superar la atomización territorial y administrativa municipal.

Esta situación amplifica el problema destacado por el Libro Blanco cuando habla del papel del legislador sectorial y de un futuro de vaciado de competencias de las entidades locales que muchas veces no se reconocen y solo se delegan; en otros casos solo tienen un papel gestor (con imposición de controles, tutelas o medidas de coordinación exageradas en su interés general); 0 se incrementan las responsabilidades, pero no los recursos. Situaciones todas ellas que permiten las disfuncionalidades atribuidas a la LRSAL cuando dispone de la complejidad de la difusión de responsabilidades de los gobiernos locales en sus ejercicios y los ámbitos en los que operan. Situaciones que se traducen en un aumento de las competencias impropias y las prestaciones extraordinarias para suplir los desequilibrios que causa esta delegación no regulada por el sistema presupuestario.

Sin embargo, debemos considerar los fallos que el Libro Blanco ve en la LRBRL 7/1985 en cuanto a la modernización de las prestaciones obligatorias según población. De este modo, se exige una restricción de las materias que se atribuyen a las Administraciones Locales o una base de potestad pública ya no basada en el interés local sino en la población. Con ello se consigue una homogeneidad que pone en una situación de pérdidas democráticas y constitucionales el sistema autonómico y regional. Esto se debe a la pérdida del principio primero del entramado administrativo español otorgado por la Constitución española, y a la entrada en contradicción con el carácter principal de bases del régimen local dado por la Carta Europea en su art. 6.1: Potestad de auto-organización de cada ayuntamiento a determinar sus órganos complementarios.

Esta reforma pone, en principio, en manos de la Diputación Provincial la gestión de las prestaciones de servicios mínimos en poblaciones inferiores a 20.000 habitantes. Lo cual supone 7.728 municipios, ya que solo 384 superan esta cifra.

En cuanto a la otra entidad dentro de régimen local administrativo, se garantiza la autonomía de las provincias. Ningún legislador puede demandar ni declarar anticonstitucional la autonomía de una Provincia ya que así lo dice la misma Constitución Española. La autonomía de las provincias es más reducida que la de los municipios y con contenidos diferentes, garantizando unas competencias mínimas y su autonomía relativa. No obstante, el legislador estatal puede modificar el contenido de las competencias, pero no puede suprimir la institución provincial. Esta entidad local provincial detenta las funciones de colaboración, cooperación y ayuda a los municipios, respaldada por cierta autonomía de gasto. El sentido de autonomía muchas veces es equivalente, mutatis mutandis, con la autonomía de gasto. Por ello, puede afirmarse que la autonomía provincial es, en gran medida, autonomía financiera (en su vertiente de poder de gasto). El poder presupuestario provincial constituye, así, el núcleo duro de la autonomía provincial. Si se tiene en cuenta que el presupuesto de las provincias no es ilimitado, como tampoco lo es su disponibilidad financiera, no cabe duda que la función central de la provincia, $y$, en general, también de todas las entidades que integran el segundo nivel local, es la de cooperación y asistencia a los municipios. 
Podemos concluir que el principal objetivo de estas entidades de segundo nivel es reforzar a los municipios. La intervención de la provincia, en su función de complemento de la falta de capacidad del municipio cuando sea necesario, sería la clave para fijar la competencia en el nivel local, evitando su desplazamiento a la comunidad autónoma. $Y$ en otros casos, permitirá la mejora de la calidad de los servicios que vengan prestando los municipios. La LRSAL da mucha importancia al papel de las provincias en tema de complementación de los servicios municipales, o mejor dicho, la provincia absorbe en muchas ocasiones las competencias propias de los municipios. Esta medida invierte la tendencia general de descentralización de las competencias, como ya hemos analizado en abundancia.

\section{La formación del empleo público local}

La relación entre provincia y municipios puede interpretarse también de manera ambigua. La provincia es la agrupación de municipios, aspecto que acerca mucho los objetivos de la provincia a los de los municipios. Aquella ha sido concebida como órgano de soporte a las competencias de los municipios y como representante de los intereses locales frente a terceros sujetos. La condición de elección indirecta es una demostración de este principio. La representación municipal a través de la provincia podría articularse de formas distintas, es decir, como representantes de las entidades locales.

La formación, por parte de la provincia, de los equipos técnicos y profesionales de apoyo a los representantes locales en los órganos de otros niveles de gobierno, y en ámbitos no formales, así como el desempeño de una función de coordinación y colaboración entre los otros niveles de gobierno y el nivel local, son atribuciones naturales de las provincias. Las directrices de la Constitución se interpretan según las preferencias aparentes de las autonomías por otras formas de representación municipal. Por ejemplo, en el caso de la Comunitat Valenciana se apuesta por una comisión mixta Generalitat-Federación Valenciana de Municipios y Provincias (FVMP); en Cataluña se opta por un consejo de gobiernos locales; en Andalucía por una colaboración entre Junta y Ayuntamientos, etc.

\section{Competencias: Gobernanza territorial}

La autonomía, garantizada por la constitución del 1978, implica la necesidad de que todo el territorio nacional se organice en municipios y provincias; el reconocimiento de una esfera de intereses propios y la atribución de competencias de gestión. Supone también la auto-selección de sus órganos de gobierno y la suficiencia económica para el ejercicio de sus competencias (art. 142 CE). La crisis económica del 2008, ha puesto de relieve las deficiencias de la normativa establecida desde la 7/1985, 2 de abril, LBRL, en la eficiencia del modelo municipal español, lo que abre una línea de discurso centrada en la "racionalización" y "sostenibilidad" municipal, empleada para la reforma competencial en la actual ley de Administración Local 27/2013 del 27 de diciembre.

La gobernanza local siempre ha sido considerada el gran problema de las 
Corporaciones Locales (Mir, 1998). Una razón para ello es la descoordinación y la generación de duplicidades en el suministro de servicios como consecuencia del desalineamiento de la administración estatal y local con el modelo de organización autonómico impulsado por la Constitución. Además, las CCAA han reproducido el modelo estatal, reiterando muchas de las competencias estatales, lo que genera aún más confusión, solapamiento de competencias y expansión excesiva de la estructura burocrática de las autonomías.

La falta de colaboración y organización entre los distintos niveles de administración ha producido una expansión del sector público, del número de funcionarios y del gasto. EI carácter paternalista del Estado, de la administración central, ha dificultado el desarrollo de un sistema de administraciones locales eficientes y autónomas. Es necesario construir un sistema de integración vertical y horizontal de los distintos niveles de administración basado en la cooperación, lealtad y solidaridad entre los actores de gobierno.

Uno de los objetivos de la LRSAL es la reducción del número de municipios. España posee un mapa municipal muy fragmentado, con muchos municipios muy pequeños. Esta realidad puede favorecer problemas de eficiencia en la provisión de servicios o un gasto excesivo por municipio. Por ello, las reformas de la administración local han perseguido la agrupación de municipios en muchos países, como ocurre en la mayoría de los miembros de la UE.

La indefinición de las competencias de las CCAA es otra razón, además de la falta de cooperación, por la que existen problemas en la administración pública. La misma Constitución propone un listado de competencias exclusivas del Estado, pero no así de las autonomías, con lo que habría que considerar que las competencias que no son del Estado corresponden a las CCAA. De hecho, el artículo 149.1 de la Constitución afirma que todas las competencias que no son estatales y que no se han tomado, por estatuto, por las autonomías, quedarán en manos del Estado. Como consecuencia de este vacío institucional, muchas veces se han presentado conflictos de competencia ante el Tribunal Constitucional. Las razones están también en la transversalidad de algunas medidas que se pueden tomar o en la interferencia con competencias sectoriales. El problema de los gobiernos locales es su doble relación con Estado y CCAA, ya que deben responder a los dos niveles de administración. Si la regulación competencial es defectuosa, el marco de actuación local será aún menos claro: las tensiones entre los niveles superiores de gobierno limitan la capacidad de maniobra de los gobiernos locales.

\section{Financiación de las Entidades Locales}

En la actualidad, el sistema tributario local se caracteriza por el arraigo de bases imponibles poco flexibles e impopulares. La distribución intergubernamental de los recursos financieros ha sido motivo permanente de conflicto, que se ha tratado de solventar sobre la base de largas negociaciones, cuyos resultados, lejos de responder a criterios de justicia, reflejan la distribución territorial del poder político. A ello hay que añadir, en lo que respecta al nivel local de Gobierno, la persistencia de importantes inequidades horizontales, mantenidas (y agravadas) históricamente por un esquema de transferencias sustentado en la Participación en Ingresos del Estado (PIE) como 
elemento nuclear, cuyos criterios de distribución beneficiaron (en términos relativos) excesivamente a las grandes ciudades, y originaron resultados extrañamente dispersos en lo que respecta a los pequeños municipios.

Otro asunto es el escaso papel de las CCAA en el ámbito de la financiación local. Las cifras de financiación per cápita recibida ponen de manifiesto una clarísima discriminación a favor de los municipios radicados en territorios con regímenes fiscales especiales, que les han permitido con sus excedentes mejorar la financiación de sus localidades, caso de los territorios forales (País Vasco y Navarra) y, también, de las Islas Canarias.

En tema de deuda pese a los prejuicios instalados en las conciencias de los ciudadanos, no parece ser percibido como un problema generalizado de los municipios españoles: de los más de 8000 municipios que hay en España, 665 acumulan el 90 por ciento de la deuda local, la mitad de los municipios deben menos de 100 euros por habitante, y 3076 de ellos no deben absolutamente nada.

\begin{tabular}{|l|r|r|r|r|r|r|r|r|}
\hline \multirow{2}{*}{$\begin{array}{c}\text { Año/ } \\
\text { Trimestre }\end{array}$} & Deuda AAPP & Deuda AAPP\% & \multicolumn{2}{c|}{ Administración Central } & \multicolumn{2}{c|}{ CCAA } & \multicolumn{2}{c|}{ Corporaciones Locales } \\
\cline { 7 - 9 } & Importe & PIB & Importe & \% PIB & Importe & \% PIB & \multicolumn{1}{c|}{ Importe } & $\%$ PIB \\
\hline 2012 I & 775.848 & 74,4 & 655.323 & 62,8 & 147.358 & 14,1 & 36.860 & 3,5 \\
\hline 2012 II & 805.521 & 77,6 & 680.194 & 65,5 & 169.218 & 16,3 & 44.982 & 4,3 \\
\hline 2012 III & 818.071 & 79,1 & 695.477 & 67,2 & 168.407 & 16,3 & 43.801 & 4,2 \\
\hline 2012 IV & 884.731 & 86,0 & 760.195 & 73,9 & 185.456 & 18,0 & 41.939 & 4,1 \\
\hline 2013 I & 924.132 & 90,0 & 797.202 & 77,7 & 190.525 & 18,6 & 42.779 & 4,2 \\
\hline 2013 II & 943.872 & 92,2 & 818.697 & 80,0 & 194.088 & 19,0 & 43.153 & 4,2 \\
\hline 2013 III & 954.947 & 93,3 & 831.676 & 81,3 & 196.687 & 19,2 & 41.770 & 4,1 \\
\hline 2013 IV & 960.640 & 93,9 & 836.127 & 81,7 & 206.797 & 20,2 & 41.490 & 4,1 \\
\hline
\end{tabular}

Fuente: Ministerio de Hacienda y Administraciones Públicas.

Con la crisis el nivel de financiación de los municipios ha descendido, una parte por causa de impuestos municipales, que inflaron mucho los recursos financieros disponibles: IBI, impuestos sobre edificación y de desarrollo urbano, así como otras tasas compartidas: IVA, IRPF y otras. A ello hay que añadir la caída general de la PIE, vinculada a los Ingresos Tributarios del Estado.

Las AALL se enfrentan a importantes dificultades a la hora de recaudar recursos, como consecuencia de los aspectos señalados, a los que hay que añadir la dependencia financiera de Estado y CCAA. La nueva reforma de la LBRL no se puede considerar buena por cuanto trata a los más de 8000 municipios de la misma manera. Conforme al principio técnico de proximidad, entendemos que cada Parlamento autonómico se erige en el legislador que está más cerca de los municipios que integran la respectiva comunidad autónoma, $y$, por consiguiente, es el que está en mejores condiciones de definir el respectivo sistema financiero, considerando las diversas tipologías de entes locales concurrentes en su territorio. Igualmente, el Estado no debería penalizar las capacidades de captar mayores recursos financieros por medio de tasas que algunos municipios podrían ser capaces de implementar. Por consiguiente, los municipios deberían tener más autonomía a la hora de establecer la imposición fiscal, como por 
ejemplo en el caso del $\mid \mathrm{BI}$, de la $\mid \mathrm{AE}$, sobre el tráfico, medio ambiente, etc. En general se trata de conferir más autonomía fiscal a los ayuntamientos, de manera que establezcan las necesidades y las medidas en ámbito fiscal y de Hacienda Local.

El inframunicipalismo que define el mapa administrativo español, hace que las empresas que suministran servicios públicos no puedan conseguir economías de escala, lo que conlleva perdida de eficiencia y de recursos financieros, o que parte de la ciudadanía no tenga la posibilidad de acceder a algunos servicios básicos. El reto de reforma de la AP es el de adaptar el sistema y la estructura administrativa a las necesidades de cada territorio y ciudadanía.

Este trabajo de regulación de las competencias a nivel local podría pertenecer sobre todo a instituciones que, a pesar de que cuentan con un tamaño suficiente, detienen relaciones y conocimientos muy fuertes del funcionamiento del territorio y de sus aspectos socio-económicos, geográficos y culturales más peculiares. Estas instituciones podrían ser las CCAA, mientras que, en la organización y la ejecución de algunas competencias, como la de carácter más social (servicios sociales, educación, asistencia sanitaria) las entidades locales de tamaño superior al municipio e inferior a la provincia podrían resultar esenciales (mancomunidad, ente comarcal, etc.). A menudo, las diputaciones gestionan un territorio demasiado grande, heterogéneo y con escasas características comunes. Además, la población de una comarca o mancomunidad permitiría una gestión más eficiente y financieramente sostenible de los servicios locales, gracias a la generación de economías de escala.

La reforma no considera la posibilidad de establecer un sistema de reparto de competencias más flexible y adaptado al territorio. Además, se echa en falta una intención explícita de construir un sistema sólido y proficuo de colaboración interinstitucional vertical y horizontal. El modelo planteado por la reforma denota una clara falta de integración con la realidad territorial y de cooperación intergubernamental, pero, sobre todo, ignora la realidad y necesidades del ciudadano.

La estabilidad presupuestaria y el equilibrio financiero es un objetivo muy importante, y conditio sine qua non para las AAPP, pero hay que tener en cuenta a la hora de hacer una reforma de las AALL que el objetivo primario es mejorar de manera efectiva las condiciones de vida de los ciudadanos y el desarrollo de la sociedad. Una reforma de las AALL debería reforzar la delegación de competencias, por medio de convenios estables entre CCAA y municipios asociados o diputaciones provinciales reformadas.

Se requiere una administración única, integrada, sincronizada, inter-operativa y coordinada. Aplicar el principio de subsidiariedad pronunciado por la constitución. Reforzar la autonomía local es la política también de la Unión Europea y de las democracias más maduras y estables del mundo occidental. El principio de subsidiariedad tiene que ser complementado por la capacidad de gestión; una gestión que tenga como objetivos los de la ciudadanía.

\section{Los cambios que aporta la ley}


La Ley 7/1985 de 2 de abril, Reguladora de la Base de Régimen Local (LBRL) ha generado una serie de disfuncionalidades que se concretan en duplicidades y solapamientos como consecuencia a la realización, por parte de los ayuntamientos, de actividades y servicios sin un título competencial completo, y que traen aparejada la financiación correspondiente. Como consecuencia se produce la difusión de las responsabilidades y la confusión con las responsabilidades de otras AAPP. Otras consecuencias son la dificultad de los ciudadanos en asignar con certeza las responsabilidades, la estabilidad financiera del conjunto competencial propio y de las competencias delegadas y acordadas mediante convenios. Por consiguiente, se determina en la ley que los convenios para la delegación de las competencias se acompañen con una dotación presupuestaria completa por un periodo de al menos 5 años.

La reforma destaca sobre todo por la inserción de los principios de eficiencia y eficacia, vinculados a los de estabilidad presupuestaria y sostenibilidad financiera. El suministro de competencias impropias por parte de los municipios, solo se podrá ejercer cuando no se ponga en riesgo la estabilidad financiera de la Hacienda municipal (estabilidad presupuestaria y sostenibilidad financiera), y cuando no se incurra en la duplicación del servicio. Por lo tanto, serán necesarios informes previos de la AP competente en la materia y de la AP que tenga atribuida la tutela financiera (art. 7).

Una parte importante de la reforma es la que se refiere a la fusión de municipios y a la creación de nuevos, que tendrán una población mínima de 5000 habitantes. Se configuran incentivos financieros presupuestarios para los ayuntamientos que deciden fusionarse, siempre bajo la supervisión de Estado y de la respectiva CCAA. Se suprime la redacción anterior de que los municipios pueden promover toda clase de actividades. La descentralización de servicios sigue siendo posible, pero queda estrictamente vinculada a la disposición de recursos financieros suficientes para el suministro del servicio por parte de los municipios. Por lo tanto, la delegación, o la descentralización de los servicios, deberá contar con una memoria económica que refleje los impactos sobre los recursos financieros de las AAPP afectadas. Todo ello si no se produce una atribución simultanea de competencias.

Entre todas las competencias municipales, parece que los servicios sociales son los más dañados por la reforma, quedando solo en los municipios con más de 20.000 habitantes como forma de "evaluación e información de situaciones de necesidad social y la atención inmediata a personas en situación de riesgo de exclusión social". Naturalmente, el cambio más importante que aporta la reforma es que numerosas competencias pasan a las diputaciones en los ayuntamientos con menos de 20.000 habitantes: recogida y tratamiento de residuos, abastecimiento de agua potable a domicilio y evacuación de aguas residuales, limpieza viaria, acceso a núcleos de población, pavimentación de las vías urbanas y alumbrado público. La prestación de los servicios será directamente de la diputación, o compartida a través de consorcios de municipios, mancomunidades u otras fórmulas, siempre bajo la supervisión de un informe de la CA y del Ministerio de Hacienda y AAPP. El municipio puede mantener el servicio si justifica ante la diputación que puede prestarlo con coste efectivo menor que la forma de gestión propuesta por la diputación o equivalente. El cálculo del coste tiene que ser en coste efectivo del servicio. En la reforma (art. 27) también se habla de delegación de competencias estatales y autonómicas a los municipios, evitando 
duplicidades y logrando mayor transparencia en el suministro de los servicios. La delegación será de un plazo no inferior a los 5 años, obviamente en el respeto de la estabilidad presupuestaria y de la hacienda local. Muchas de las competencias listadas en este artículo pertenecen a servicios que ya se suministran en algunas ciudades y que no son de carácter obligatorio. Por lo tanto, en la reforma se precisa el sistema de los convenios, estableciendo un sistema de financiación en caso de delegaciones más puntual y controlado. La complementación de los servicios será posible en la medida de que se garantice la estabilidad presupuestaria y la sostenibilidad financiera.

Uno de los cambios más importantes que ha aportado la ley es el mecanismo de cálculo del coste de los servicios, que ha pasado de "coste estándar" a "coste efectivo". En general se refuerza el control del Estado y de las respectivas CCAA sobre el trabajo de los ayuntamientos y diputaciones. El refuerzo de sistemas de control intergubernamentales se explicita con la obligación de presentar informes y análisis de los servicios públicos. Esto contradice uno de los principios básicos que es la subsidiariedad y tampoco hace realmente más transparente y eficiente la administración. 


\section{El impacto previsible de la LRSAL de acuerdo con los actores implicados}

Hasta el momento se ha ofrecido una perspectiva técnica a partir del análisis de documentos y de la legislación pertinente. Con el fin de obtener una visión lo más completa posible del impacto de la implantación de la LRSAL, se ha estimado conveniente complementar este enfoque técnico con la opinión de una muestra de actores representativos de los diferentes colectivos implicados en la gestión de la administración local. Para ello se ha llevado a cabo una encuesta que trata de cuantificar y graduar las opiniones del universo al que acontece el nuevo reglamento de gobernanza local. La encuesta, nos ha permitido recoger los resultados de una muestra representativa a través de una batería de preguntas. Estas preguntas responden a una serie de hipótesis recogidas entre expertos y profesionales de diversos campos del desarrollo local y gobierno local en torno a los impactos previsibles de la implantación de la ley 27/2013 del 27 de diciembre.

La encuesta es anónima para facilitar una respuesta veraz y objetiva, y contiene 25 preguntas estructuradas en temas relacionados con la LRSAL como competencias/duplicidad, estabilidad/sostenibilidad económica y presupuesto, prestaciones sociales, y opiniones sobre los beneficios o defectos de la Ley. Todo ello acotado en 6 preguntas de tipo abierto y 19 de tipo cerrado, entre las cuales 9 son preguntas exhaustivas y abarcan todas las posibilidades, y 10 excluyentes de categorización independiente. Las encuestas se realizaron de forma telemática (online) para ampliar la probabilidad de respuesta, maximizando el tiempo y minimizando el coste de su realización a esta escala. La fase de recolección de datos comenzó, el 26-27 de noviembre del 2014 hasta su fecha de finalización el 20 de febrero del 2015.

El tamaño de nuestra población conocida es de 450 individuos, delimitada en segmentos de trabajadores del sector público y en el ámbito territorial de la Comunidad Valenciana. Para ello se ha seguido la proporción de funcionarios pertenecientes al grupo A1 y A2 dentro de cada uno de los órganos municipales de planificación, coordinación y dirección -según las competencias delegadas en la LRSAL- para acotar nuestro universo a cifras que permitan definir la muestra. Esto nos ha permitido, además, seleccionar los actores más adecuados para formar parte de la muestra primaria, a saber, los profesionales municipales superiores técnicos y políticos. En concreto, la muestra consta de personal de la estructura política deliberante (interventores-tesoreros, secretarios y secretarios-interventores), personal de organismos supramunicipales (administración provincial), entes dependientes de una entidad local (consorcios, entidades públicas empresariales, Agencias de Desarrollo Local y Red AFIC), y entes y organismos profesionales como FVMP, COSITAL, FEPRODEL, etc., junto otros profesionales del ámbito académico.

La elección de este universo no se basa solo en la intención de demostrar la validez de las hipótesis de trabajo. Los actores y organismos públicos encuestados tienen una influencia clara en la ordenación de la capacidad de configuración de la sociedad periférica. El fondo del asunto radica en el sesgo del proceso de descentralización que no prosiguió hacia su conclusión lógica, las entidades locales. La expresión del localismo es la evolución de las regiones españolas hacía su configuración como una 
realidad provincial desde el Decreto de 30 de noviembre de 1833. Este esfuerzo periférico, refleja los logros de los entes locales por instaurar un equilibrio en sus relaciones con el centro estatal mediante sus políticas de gobierno (que no tienen por qué inferir hechos diferenciadores entre regiones sino más bien fuerzas de atracción integradoras hacia lo común). El localismo es una vía que describe el entorno caracterizado por la suma de las muchas formas que los individuos e instituciones, públicos y privados, gestionan sus asuntos comunes. Esta vía incluye instituciones formales y regímenes autorizados para imponer su cumplimiento, así como acuerdos informales entre personas e instituciones de acuerdo a sus intereses. Es lo que el Libro Blanco de la Gobernanza nos describe en palabras de J.P. Olsen como el intento de un gobierno de intervenir en la sociedad a través de la construcción de instituciones efectivas, así como los esfuerzos para desarrollarse mediante organismos que proporciones la demanda de servicios locales en crecimiento debido al avance del proceso de urbanización y los movimientos migratorios.

En relación con estos argumentos, se ha considerado necesario incluir un elenco de profesionales de rango superior de las administraciones locales, y de personal especializado en el desarrollo y asesoramiento de lo local. Este hecho se justifica por su grado de importancia a la hora de influir y ser influenciado por sus actuaciones y opiniones manifiestas en la gestión y planificación de sus responsabilidades al servicio del interés público local. Se ha limitado el universo y la muestra de análisis a las instituciones de la Comunidad Valenciana por razones operativas

\section{El procedimiento del muestreo}

A la hora de llevar a cabo una encuesta, el propósito del investigador no es describir la muestra de encuestados, sino hacer una inferencia sobre la población a la que la muestra hace referencia. En nuestro caso, el universo está compuesto por 450 personas que son las que ocupan los puestos y cargos en diversas administraciones a los que se ha hecho referencia anteriormente, en el ámbito territorial de la Comunidad Valenciana. Se ha determinado una muestra de 100 individuos para alcanzar un 95,5\% de nivel de confianza con un margen de error del 4,5\%. A partir de este universo, se ha determinado que, para conocer la opinión de nuestro objeto de estudio, nos referimos a un tipo de encuesta bietápica, estratificada por conglomerados, con selección de las unidades primarias del muestreo (profesionales) y de las unidades últimas (sector público área comunidad valenciana) de forma aleatoria proporcional, que conforman una muestra poblacional de 100 individuos.

Todas estas encuestas- las 100- se han recogido de un modo que, aun dependiendo de su distribución previa, cuentan por igual (al tratarse anónimamente). Es decir, se valora las encuestas a municipios en consecuencia a su papel de personal al servicio de la ciudadanía local en vigencia; junto a aquellos expertos profesionales que, desde su situación de asesores o investigadores de lo local, nos aporten sus experiencias o reflexiones. Todo ello, en sí mismo, debe constituir un marco de reflexión actualizado a la situación objeto de estudio.

El procedimiento de recogida de información se ha realizado utilizando un formulario on-line, mediante la aplicación "google-docs". Este procedimiento presenta, al menos, tres claras ventajas respecto de otras formas de encuesta más tradicionales: en primer 
lugar, la rapidez en poner a punto el instrumento, ya que la encuesta queda conformada como un formulario de cumplimentación automática a través de un procedimiento elemental de adaptación de un documento original de texto; en segundo lugar, existe igualmente una ventaja de economía de recursos, ya que los casos se van recogiendo mediante la cumplimentación on-line, por lo que no es necesario utilizar papel para impresión de los formularios ni desplazamiento a los lugares de realización de la encuesta; en tercer lugar, la facilidad para obtener los resultados sin tener que pasar por una parte del proceso de tabulación, ya que el propio programa nos ofrece una hoja de cálculo con las respuestas o, en su caso, categorías.

No todo en el proceso es de "color de rosa". El equipo de investigación ha tenido que realizar numerosas llamadas telefónicas al universo de referencia para animar el proceso de cumplimentación de las encuestas, mientras que la obtención de la muestra se ha dilatado durante más tiempo del que originariamente se estimaba. Por otro lado, la facilitación del proceso de tabulación es solo parcial, ya que, en cualquier caso, se requiere la realización de los procedimientos de categorización que deben trasladarse, a continuación, a una hoja SPSS para los posteriores análisis. Este proceso requiere definir, para cada variable, las etiquetas apropiadas que permitan obtener códigos que representen las respuestas de los encuestados.

\section{Resultados}

Las encuestas han seguido un proceso de tratamiento estándar. La naturaleza nominal de la inmensa mayoría de los datos no permite análisis sofisticados que vayan más allá de la descripción e interpretación de la distribución de las categorías en frecuencias y porcentajes, y algunas tablas cruzadas sobre información particularmente relevante.

\section{El perfil de los encuestados}

Durante los meses previos a la elaboración e implementación de la encuesta, el equipo de investigación organizó dos jornadas de análisis de la LRSAL. A dichas jornadas asistieron, principalmente, miembros de los colectivos de Secretarios, Interventores y Tesoreros de Ayuntamientos, Agentes de Desarrollo Local (AEDL), Agentes de Fomento de Iniciativas Comerciales (AFIC), y, en menor medida, miembros en el ámbito local de partidos políticos. Durante estas jornadas se incidió en la importancia de cumplimentar la encuesta objeto de análisis y, como consecuencia, el perfil de los encuestados se corresponde, en buena medida, con el público de las jornadas y, en todo caso, con personal de las administraciones locales que ha tenido conocimiento de esta iniciativa (ver Figura 3). En cualquier caso, destaca también la presencia de personal de la Administración Autonómica y de la diputación provincial, además de algunos expertos del ámbito universitario. Se trata, por tanto, de una muestra cualificada y representativa del sentir de algunos de los principales colectivos involucrados y/o afectados por las disposiciones de la LRSAL. 
Figura 3. Administración de la que proviene el encuestado

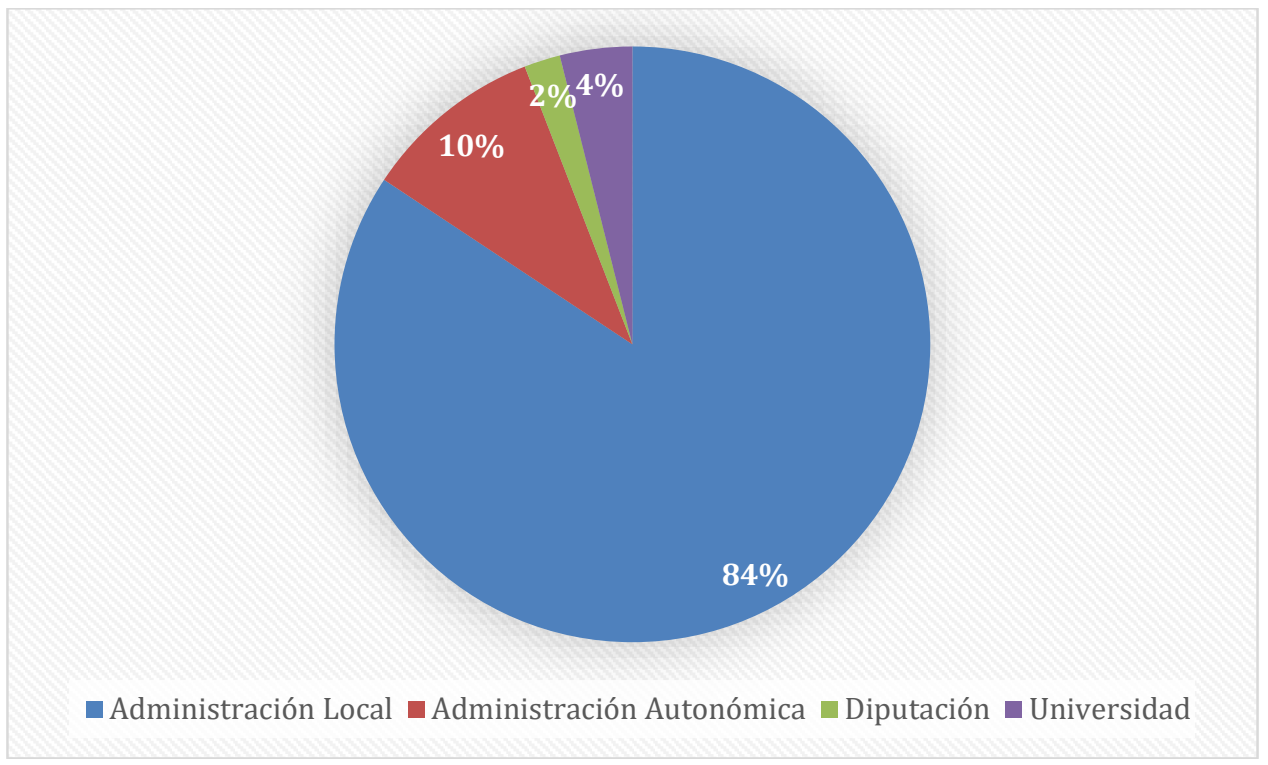

Fuente: elaboración propia

La muestra está conformada principalmente por Técnicos de la Administración General $(25,5 \%)$ y el colectivo de Secretarios, Interventores y Tesoreros de la Administración Local $(21,6 \%)$. Entre ambos grupos se conforma casi la mitad de la muestra. El colectivo técnico de la administración local se ve también representado por AEDLs y AFICs que suman cerca de un $14 \%$ más. También existe representación del sector administrativo local (cerca de un 8\%). Gerentes y Jefes de Sección, que corresponden con cargos de relevancia de la administración local y autonómica, suman un $22 \%$ de la muestra. Destaca también la escasa representación de cargos políticos de modo que representan tan solo un $2 \%$ de la muestra.

Figura 4. Cargo ocupado en su organización

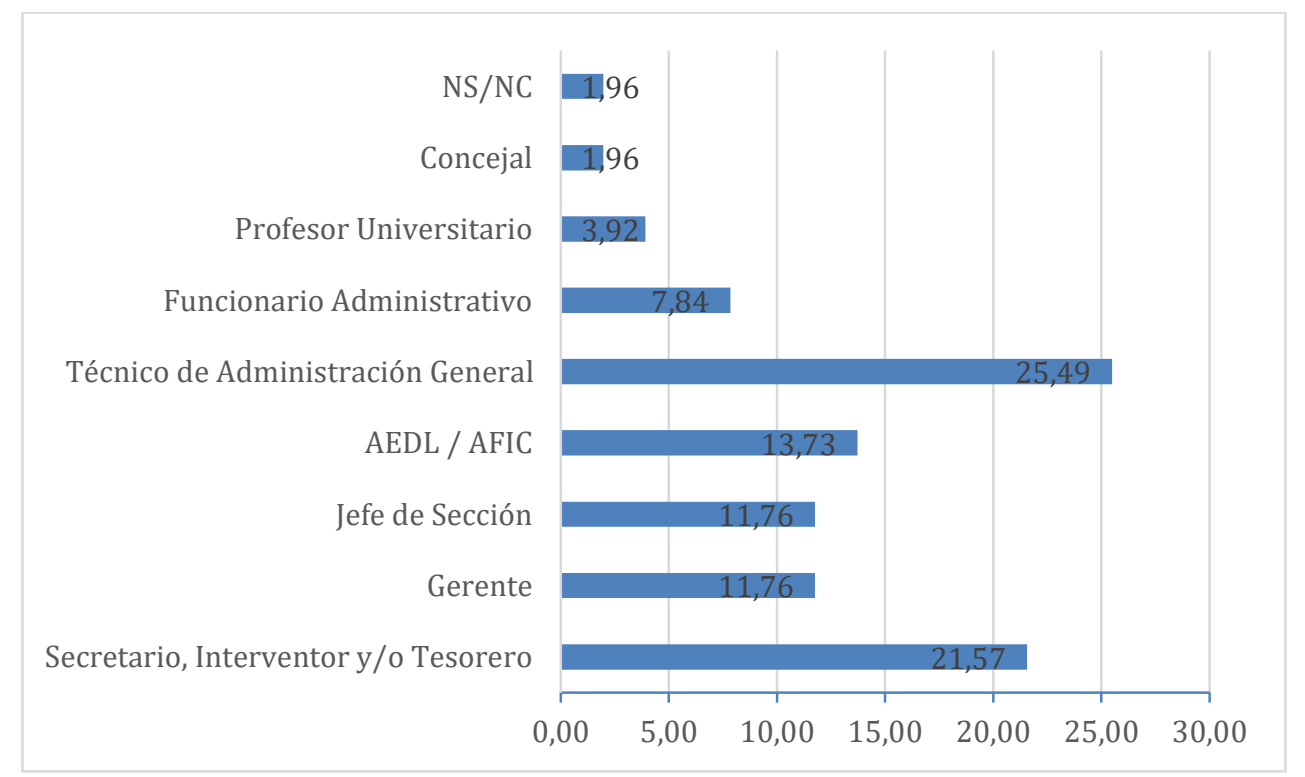

Fuente: elaboración propia 
La muestra se caracteriza por una experiencia de trabajo en las AAPP relativamente dilatada (ver Figura 5). Más del $85 \%$ de los encuestados tienen más de 5 años de experiencia de trabajo en las AAPP, y este porcentaje solo baja al $75 \%$ para encuestados con más de 10 años de experiencia. Se trata, por tanto, de un colectivo que suma muchos años de trayectoria profesional, con el valor añadido que se le supone a la experiencia a la hora de interpretar y valorar el impacto potencial de la reforma que supone la LRSAL.

En cuanto a la trayectoria profesional (figura 6), un $70 \%$ de los encuestados ha ocupado puestos diferentes a la actual. En algunos casos provienen de otras disciplinas (12\%), mientras que los tipos de puestos anteriores se parecen bastante a la distribución de cargos actuales. Esto puede deberse a que se ha considerado como "posición anterior" la misma que se ostenta en la actualidad, lo que supondría una mala interpretación de la pregunta. En todo caso, sea cual sea la interpretación dada, no se registran hechos relevantes o destacables.

Figura 5. Años de experiencia en las Administraciones Públicas

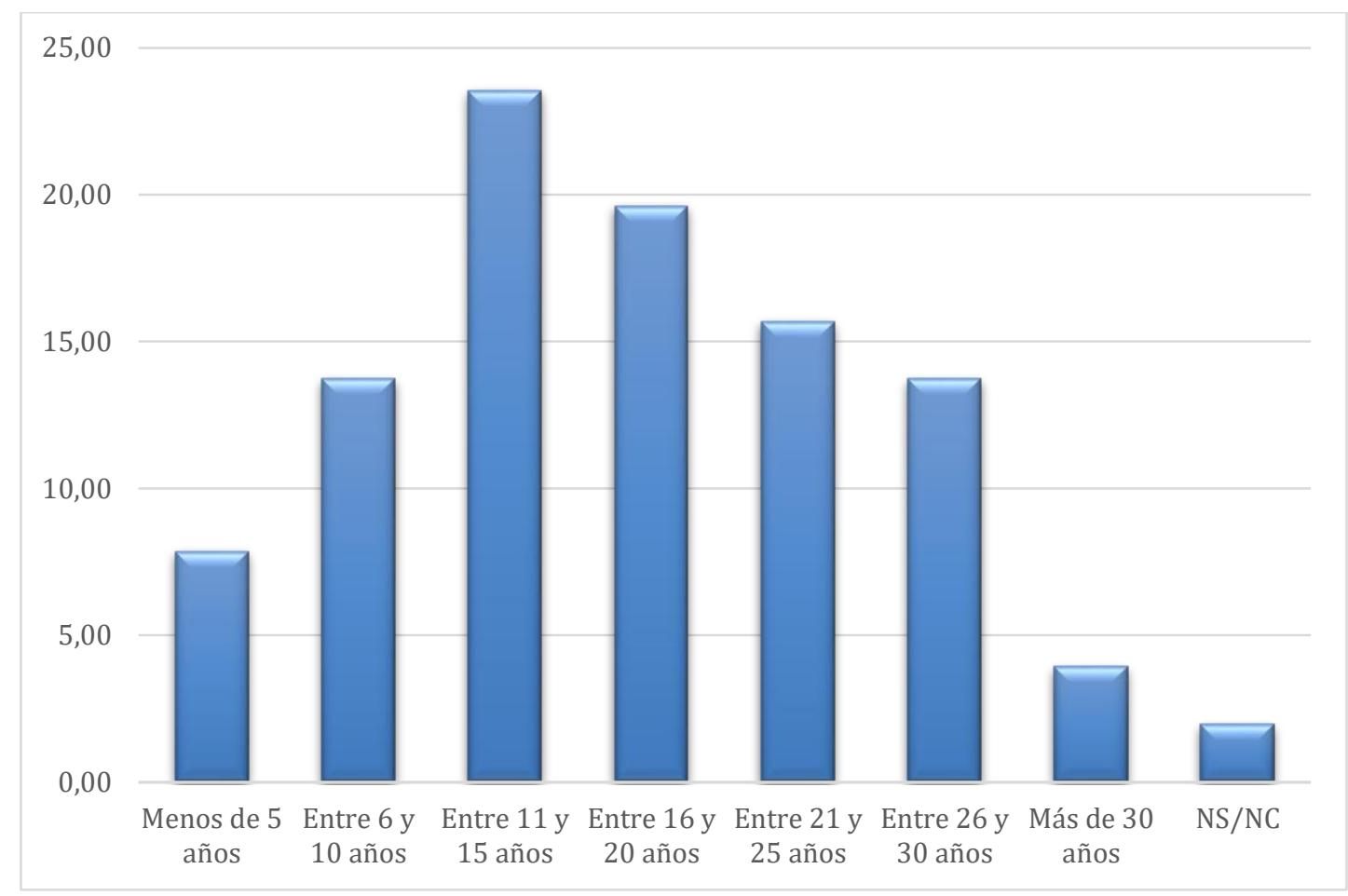

Fuente: elaboración propia 
Figura 6. Cargos desempeñados anteriormente

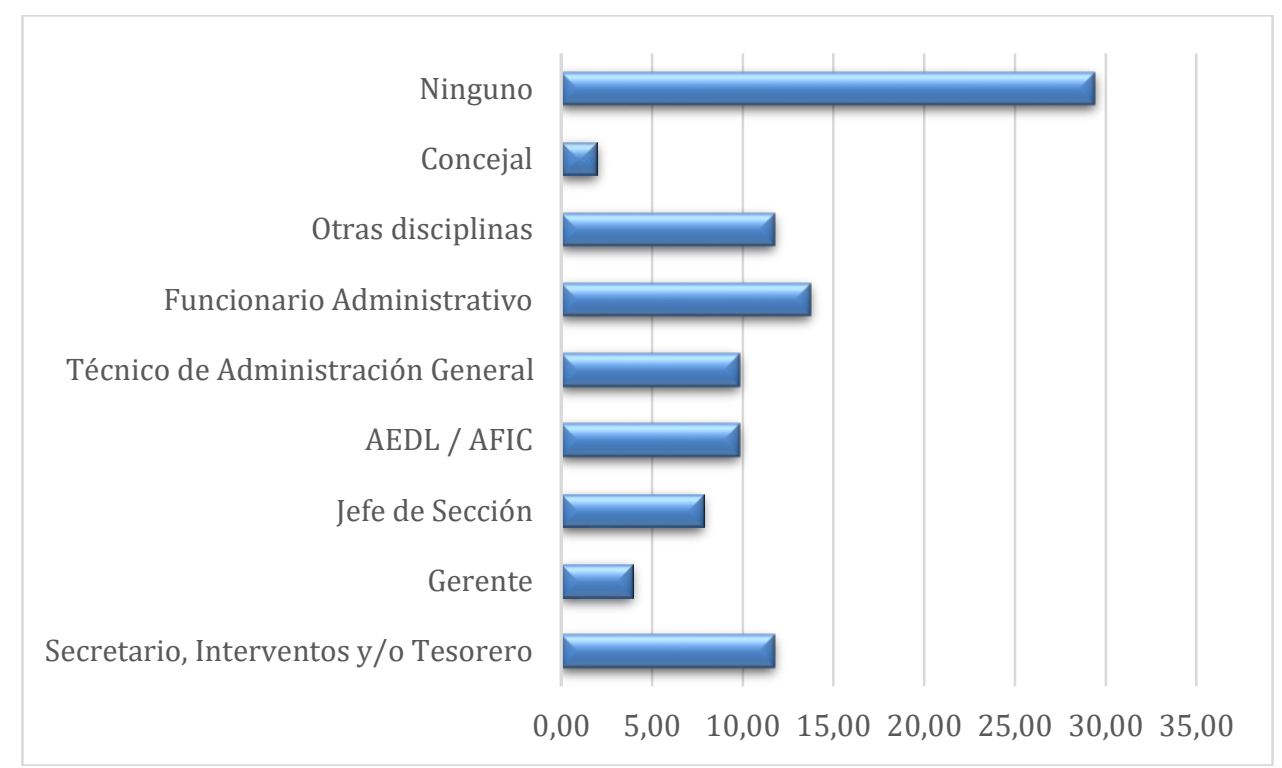

Fuente: elaboración propia

Valoración general de la LRSAL

La mayoría de los encuestados muestra una valoración negativa de la reforma que supone la LRSAL (60\%), o una valoración ligeramente positiva (35\%). Solo un $6 \%$ responde que la LRSAL implica una mejora importante con respecto a la Ley de Bases de Régimen Local de 1985 . Sin embargo, un $26 \%$ de los encuestados califica la reforma como un "cambio catastrófico".

Figura 7. ¿¿En qué medida la LRSAL representa una mejoría con respecto a la Ley de Bases de Régimen Local?

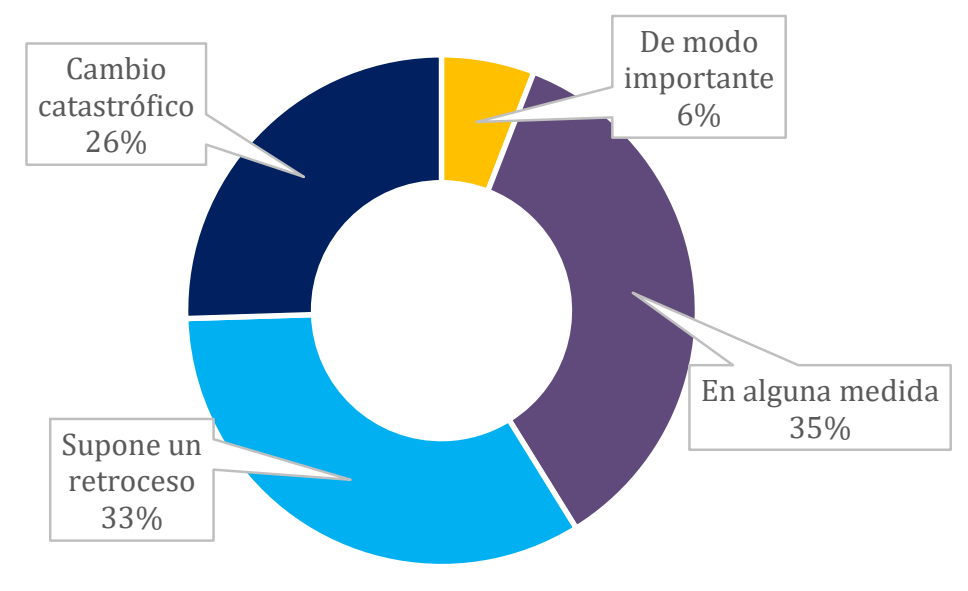

- De modo importante - En alguna medida - Supone un retroceso - Cambio catastrófico

Fuente: elaboración propia 
Se ha preguntado a los encuestados sobre los principios que comparten con el legislador en la formulación de una Ley de Administración Pública Local como la LRSAL (ver Figura 8). El principio "una competencia, una administración" es el más compartido por los encuestados (17\%). También es compartido el hecho de otorgar una "Financiación equilibrada y eficaz en las competencias otorgadas" (13\%), así como "evitar duplicidades en la prestación de servicios" (12\%). En los tres casos, se incide en la idea de racionalizar la provisión de servicios y el reparto de competencias entre diferentes administraciones. No cabe duda que, al menos para la muestra encuestada, esta es la principal virtud potencial de la reforma, y responde a la constatación de diversos solapamientos de competencias y en la prestación de servicios que se han registrado durante, al menos, la última década. De este modo, las numerosas infraestructuras "repetidas" indiscriminadamente en el territorio (polígonos industriales, etc.), servicios como bolsas de empleo, ventanillas de atención al emprendedor o formación para la empleabilidad constituyen ejemplos de iniciativas que se han multiplicado sin control. Además, es una evidencia sobradamente conocida que la mayoría de los Ayuntamientos han tenido que asumir numerosas competencias "impropias" en respuesta a las demandas y necesidades planteadas por la ciudadanía, o simplemente por voluntad de prestar un mejor servicio.

Otro aspecto destacable en cuanto a los principios compartidos se refiere al refuerzo de independencia de los interventores con respecto de las directrices de carácter político que puedan darse en el ámbito local. Se trata de una demanda tradicional del colectivo de Secretarios, Interventores y Tesoreros que persigue mantener la imparcialidad del posicionamiento técnico.

En el apartado de "opiniones contrarias a la reforma", destaca la que afirma que se comparten los principios que rigen la reforma, pero no los métodos para alcanzar dichos principios. Y en una postura más radical, un $13 \%$ de los encuestados afirma que no comparte ninguno de los principios propuestos por la LRSAL. 
Figura 8. ¿Qué principios comparte con el legislador en la formulación de una Ley de Administración Pública Local como la LRSAL?

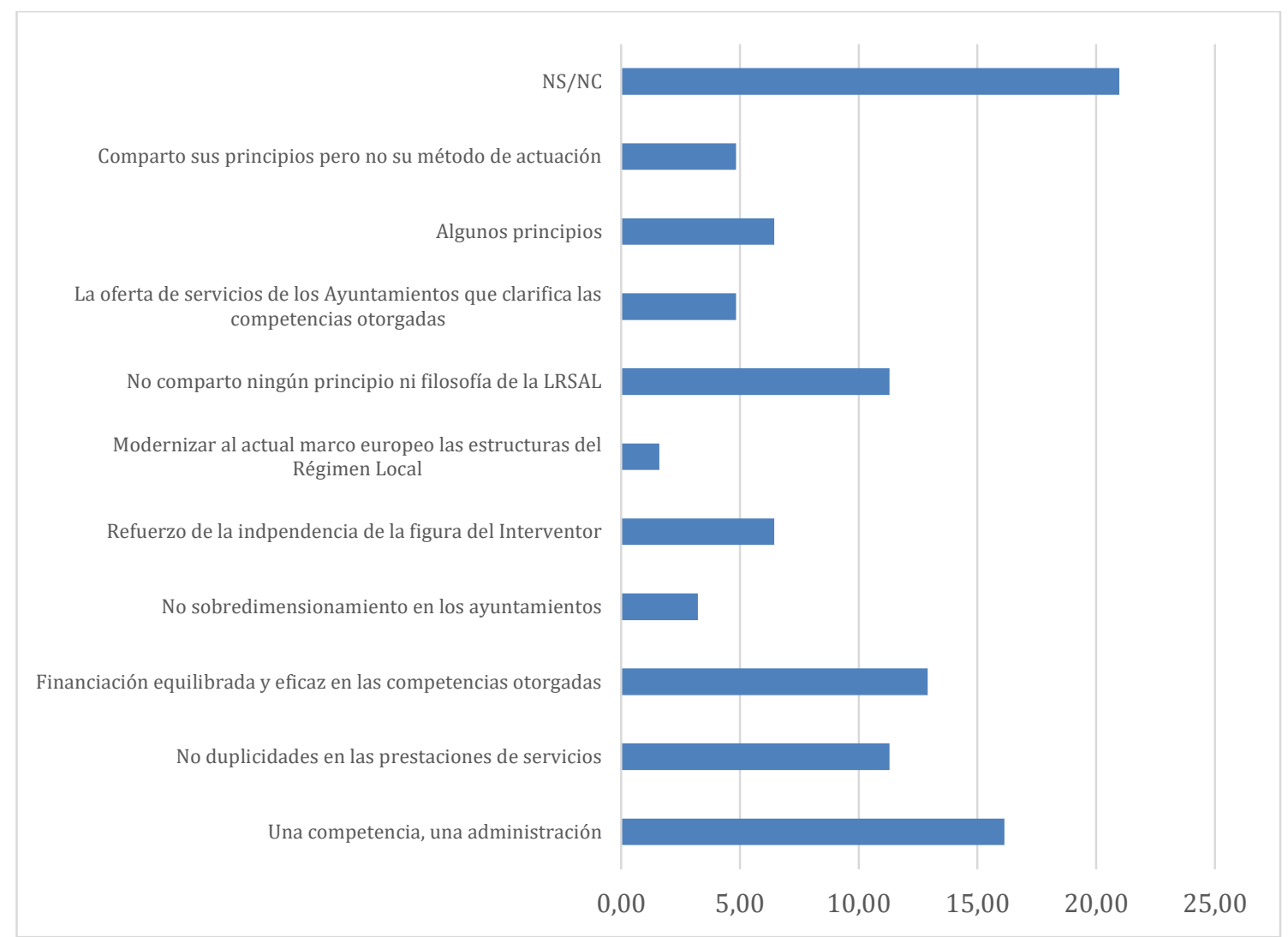

Fuente: elaboración propia

En conjunto, por tanto, de acuerdo con la opinión de la muestra, se trata de una reforma que plantea aspectos de interés y que tiene un importante potencial de impacto positivo tanto en el ámbito financiero como en la organización y racionalización de las competencias, pero que "falla" a la hora de proponer los métodos para alcanzar sus objetivos.

\section{La prestación de servicios a la ciudadanía en la LRSAL}

Uno de los objetivos prioritarios de la LRSAL es mejorar la eficiencia en la prestación de servicios a los ciudadanos. Siendo el equilibrio presupuestario la piedra angular de la reforma, es posible que el incremento de la eficiencia en la prestación de los servicios tenga repercusiones en la eficacia con la que se produce la prestación y en la calidad del propio servicio. La encuesta realizada incluye una pregunta destinada a conocer el tipo de mejoras y deterioros que se derivan de la aplicación de la reforma a nivel de prestación de servicios a la ciudadanía (ver Figura 9). Si analizamos las respuestas, vemos que predominan las que otorgan a la reforma una valoración negativa en cuanto a su impacto en la prestación de servicios. De este modo, las respuestas que suponen valoraciones negativas de la LRSAL en cuanto a prestación de servicios, suman un $80 \%$ del total, mientras que el $20 \%$ restante opta por respuestas que asocian la LRSAL a un impacto positivo en la prestación de servicios. 
Figura 9. ¿Qué tipo de mejoras y deterioros se derivan de la aplicación de la reforma a nivel de prestaciones de servicios a la ciudadanía?

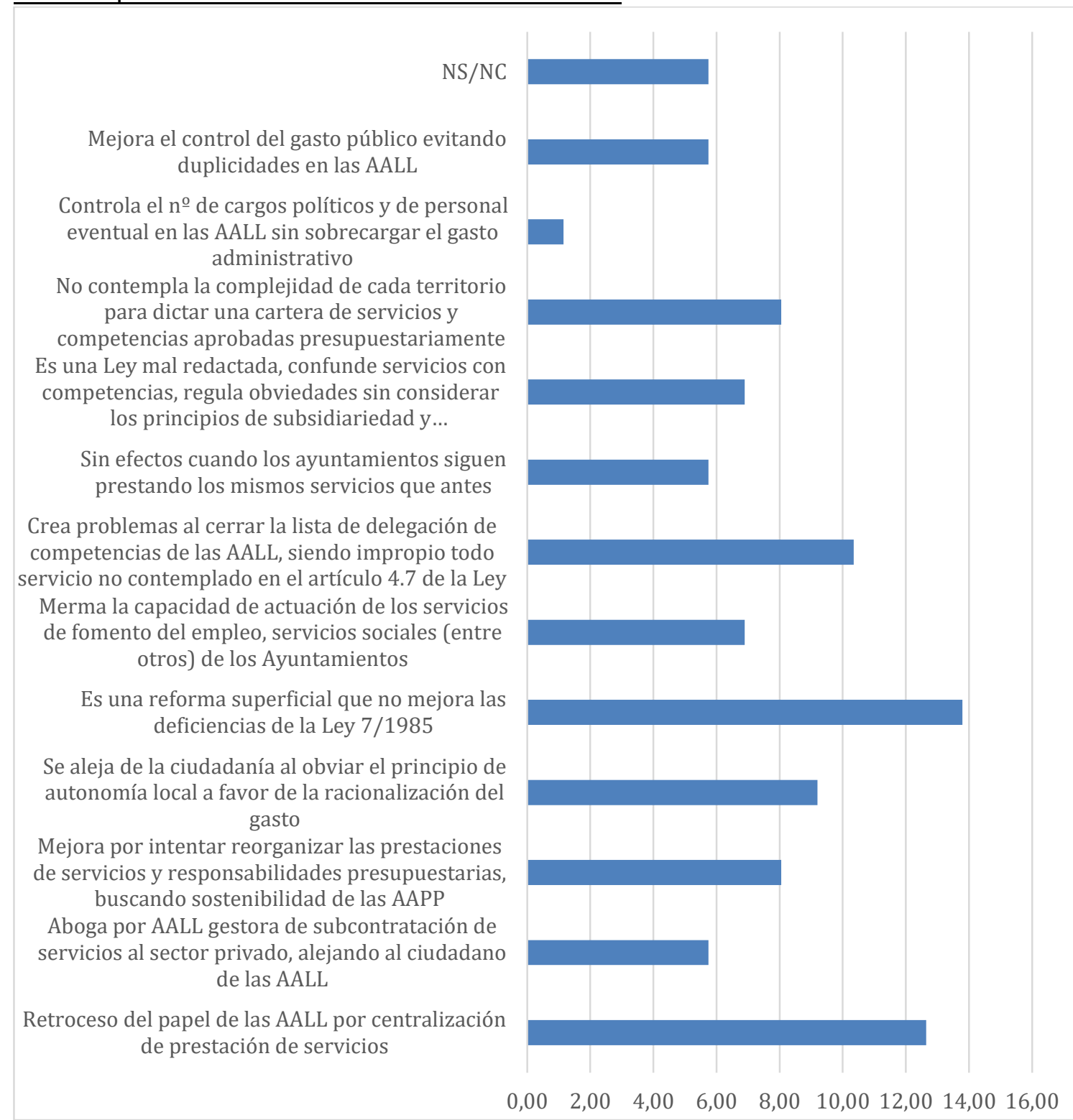

Fuente: elaboración propia

De entre todas las respuestas algunas destacan por el porcentaje obtenido. Por ejemplo, un $14 \%$ de los encuestados califica la LRSAL como una reforma superficial que no mejora las deficiencias existentes en la Ley 7/1985. En esta misma dirección, un $12 \%$ de los encuestados afirma que la Ley supone un retroceso de la función de las Administraciones Locales (AALL) por su carácter re-centralizador en la prestación de servicios. También se afirma que la Ley crea problemas al cerrar la lista de delegación de competencias de las AALL, lo cual convierte en "impropio" cualquier servicio no contemplado en el artículo 4.7 de la LRSAL (10\% de las respuestas). Importante también es la valoración de que la reforma aleja la AAPP de la ciudadanía al obviar el principio de "autonomía local" a favor de la racionalización del gasto. En muchos casos, esta situación puede poner en serio riesgo de desaparición muchos de los servicios al ciudadano que se han venido consolidando en los municipios durante los 
últimos 30 años y que, en principio, podrían calificarse como "impropios", aunque no por ello menos necesarios e importantes.

En la parte de valoraciones positivas destaca que la reforma supone una mejora al intentar reorganizar las prestaciones de servicios y las responsabilidades presupuestarias, por lo que incrementaría el grado de sostenibilidad de las AAPP (un $8 \%$ de las respuestas), o también que supone una mejora en el control del gasto público ( $6 \%$ de las respuestas). Las valoraciones positivas tienen que ver con la idea de racionalización en la asignación de competencias, lo que parece importante dados los antecedentes, aunque se adivina que, tras esa voluntad racionalizadora se esconde un intento de reducir la autonomía local, recentralizar las competencias y "atar en corto" a los ayuntamientos.

\section{Consecuencias de la reforma sobre el desarrollo local}

Sería lógico pensar que una racionalización en la prestación de los servicios públicos y el avance hacia el principio de "una competencia, una administración" conducen a una mejora general de la situación y las expectativas de desarrollo en los municipios. Sin embargo, la muestra encuestada no parece opinar así. De hecho, ante la pregunta sobre si la reforma aportará beneficios al desarrollo económico, social y cultural de los municipios, la respuesta general es que no ocurrirá así, "en absoluto" o que, en todo caso, es poco probable que ocurra. Solo una minoría de los encuestados otorga cierto margen de confianza a la capacidad de la reforma para impulsar los procesos de desarrollo local. Es probable que esta opinión, que proviene fundamentalmente de personal técnico y administrativo de los ayuntamientos, responda al temor de que la LRSAL desactive una buena parte de los mecanismos de provisión de servicios a la ciudadanía y de impulso del desarrollo local que se han ido activando desde las administraciones públicas locales. Desde este punto de vista, la LRSAL tendría un claro efecto paralizante de las dinámicas de desarrollo socioeconómico y comprometería una parte relevante del empleo local. En todo caso, es llamativo que ni uno solo de los encuestados haya afirmado que la LRSAL aportará beneficios al desarrollo local "con toda seguridad". 
Figura 10. ¿Cree que esta reforma aportará beneficios al desarrollo económico, social y cultural de los municipios?

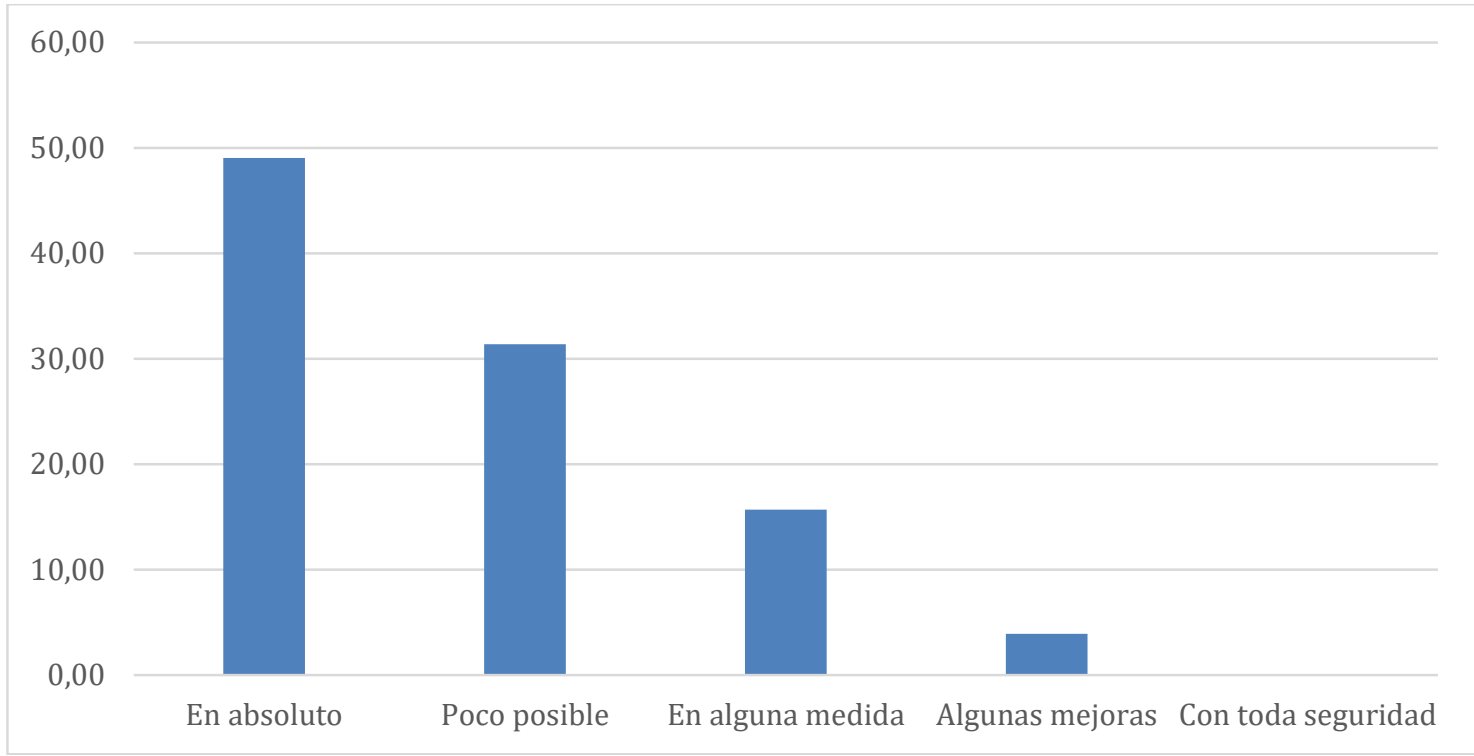

Fuente: elaboración propia

La LRSAL, la sostenibilidad financiera y la racionalización de competencias en las administraciones locales

Dos de los objetivos que definen más claramente a la LRSAL son la estabilidad presupuestaria y la sostenibilidad financiera (ver Figura 11). De hecho, ambos objetivos apuntan al principio rector fundamental de la reforma. Por este motivo se ha preguntado a los encuestados por si consideran que la reforma hará que estos objetivos sean más fácilmente alcanzables.

No es extraño que, en este caso, las respuestas tengan un tono más positivo. De hecho, más de la mitad de las respuestas apuntan que la LRSAL tendrá efectos positivos a la hora de alcanzar los objetivos de estabilidad presupuestaria y sostenibilidad financiera en las AAPP locales.

Sorprendentemente, también hay un porcentaje relevante de respuestas (45\%) que señalan que la reforma contribuirá poco o nada a alcanzar lo que podemos considerar los objetivos centrales de la reforma. ¿Se trata de una respuesta racional o es posible que las posiciones de algunos encuestados sean, de partida, contrarias a cualquier valoración positiva de la reforma? También podría interpretarse esta elevada porción de respuestas negativas como el convencimiento de que, pase lo que pase con la reforma, los servicios locales deberán continuar prestándose $y$, en este sentido, es probable que la implementación de la reforma se encuentre con dificultades irresolubles que la lleven a puntos muertos. 
Figura 11. Dos de los objetivos de la LRSAL son la estabilidad presupuestaria y la sostenibilidad financiera. ¿Cree que gracias a la reforma serán objetivos más fácilmente alcanzables para las AALL?

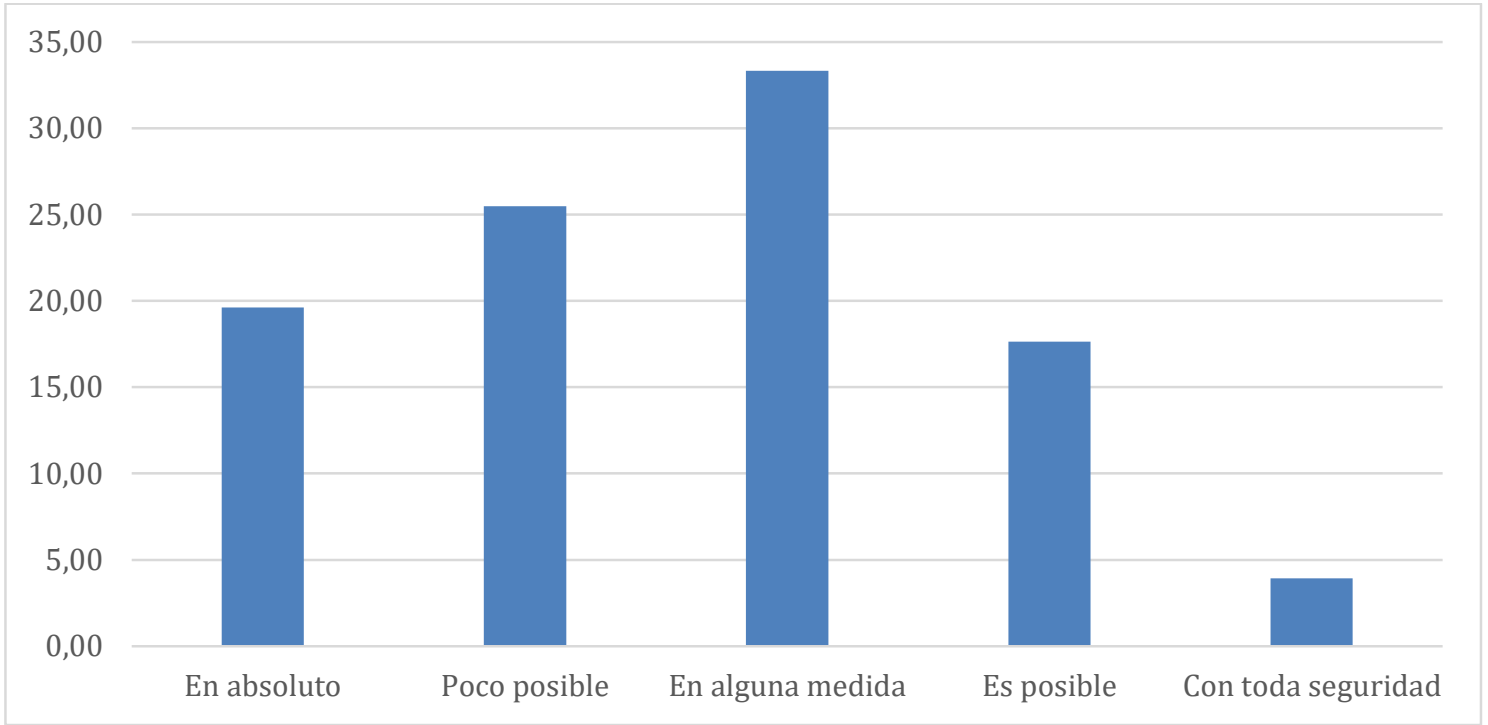

Fuente: elaboración propia

Otro de los pilares centrales de la reforma consiste en evitar que los ayuntamientos asuman, por su cuenta y riesgo, competencias impropias, y que se generen duplicidades y, por tanto, pérdida de recursos públicos en el suministro de un mismo servicio a través de diferentes niveles competenciales. A este respecto, la Figura 12 muestra la opinión de los encuestados sobre la capacidad de la LRSAL de resolver estos problemas. Son pocos los que consideran que la reforma va a tener un impacto relevante en la resolución de los problemas de asunción de competencias impropias y de duplicidad en la prestación de servicios. Tan solo un $20 \%$ piensa que la LRSAL tendrá algún tipo de impacto positivo en la consecución de estos objetivos. Sin embargo, cerca de un $50 \%$ cree que la repercusión de la reforma será escasa mientras que un $30 \%$ más opina que no tendrá capacidad alguna para dar respuesta a estos problemas. Es probable que los encuestados piensen que, de una manera u otra, las entidades locales continuarán haciéndose cargo de las necesidades demandadas por los ciudadanos, correspondan éstas a competencias propias o impropias, con independencia de las disposiciones de la reforma. 
Figura 12. El objetivo de evitar competencias impropias y duplicidades en el suministro de servicios es uno de los pilares de la reforma. ¿Cuánto piensa que la LRSAL ayuda a superar estas incongruencias?

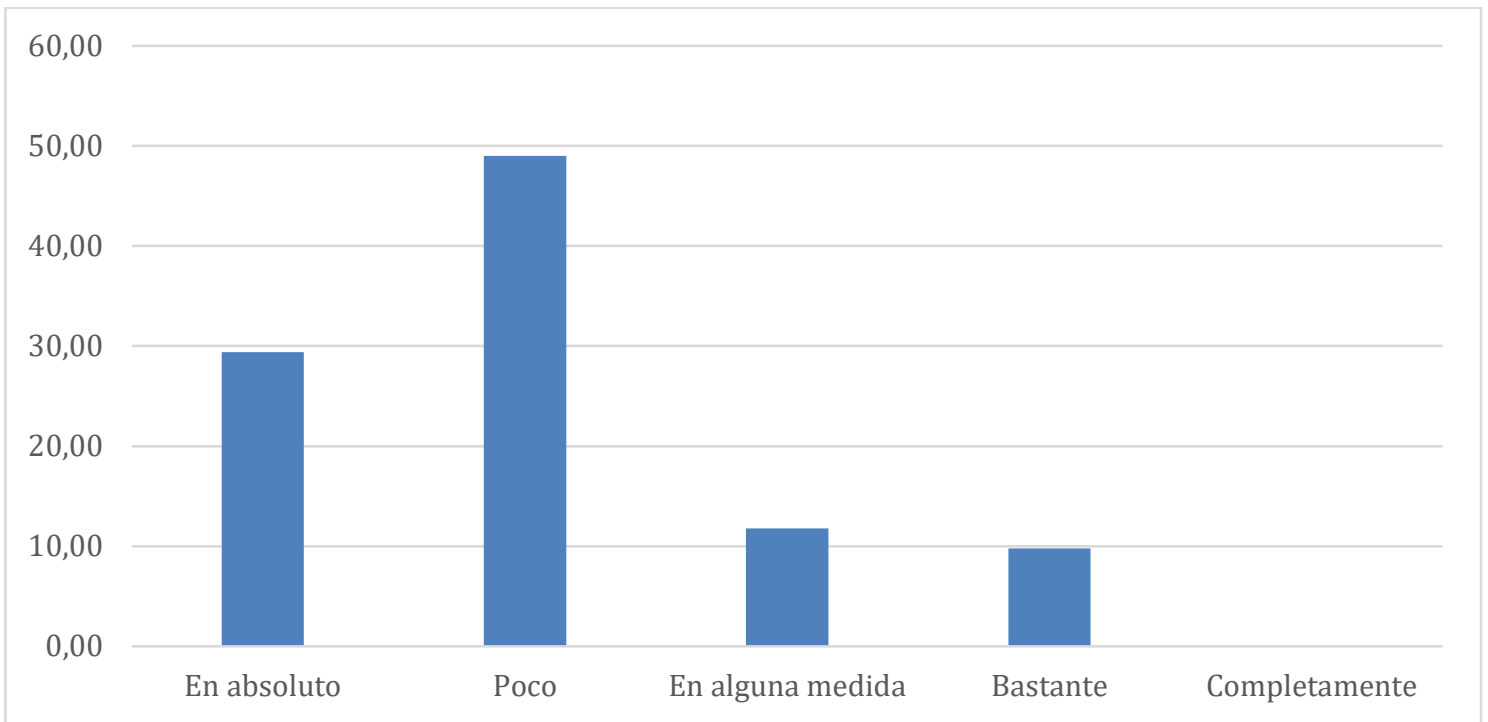

Fuente: elaboración propia

La LRSAL frente a los principios de la Ley de 1985

La Ley de Bases de Régimen Local de 1985 planteaba 4 principios fundamentales: en primer lugar, la tendencia hacia la descentralización de competencias en un contexto en el que se daba prioridad a la consolidación del denominado "estado de las autonomías"; en segundo lugar, la atribución de competencias, siempre que sea posible, a la administración más cercana al ciudadano capaz de asumirlas, en cumplimiento del principio de subsidiariedad que preside buena parte de la implementación de políticas públicas en el contexto de la UE. Además de estos dos principios, la Ley $7 / 1985$ planteaba otros dos principios casi universales como son la búsqueda de la eficacia y la eficiencia en el desempeño de las funciones de las AAPP locales. La reciente reforma pone en condicional estos principios al hacer prevalecer sobre ellos la estabilidad presupuestaria y la sostenibilidad financiera. Surge entonces una importante duda en relación a la capacidad que tendrán las AALL para mantener los principios de la Ley 7/1985 en este nuevo contexto. Las opiniones de los actores encuestados no dejan lugar a dudas. La mayoría opina que, de una u otra forma, los principios de la Ley $7 / 1985$ se verán afectados negativamente, o no podrán alcanzarse, en un contexto condicionado por la estabilidad presupuestaria, al menos, contando con el punto de partida en el que nos encontramos. De hecho, tres de cada cuatro encuestados afirma que la subordinación de los principios de la LBRL del 85 a la estabilidad presupuestaria no constituye un enfoque correcto $y$, de ellos, más de la mitad (un $40 \%$ de las respuestas totales) contesta con un rotundo "en absoluto es un enfoque correcto". Sin embargo, el restante $25 \%$ de los encuestados opina que, en alguna medida, la subordinación de los principios mencionados a la consecución de la 
estabilidad presupuestaria tiene sentido y es conveniente. Existe aquí una clara disyuntiva entre quienes piensan que los principios de la Ley de 1985 son irrenunciables, y que ello puede tener un coste en términos de estabilidad presupuestaria, y los que opinan que lo que es irrenunciable es la propia estabilidad presupuestaria, cualquiera que sea su coste en términos de grado de descentralización y nivel de proximidad al ciudadano.

Figura 13. ¿Cree que es un enfoque correcto poner en cuestión y subordinar los principios de la Ley de 1985 (descentralización, proximidad, eficacia y eficiencia) a los principios de estabilidad presupuestaria y sostenibilidad financiera?

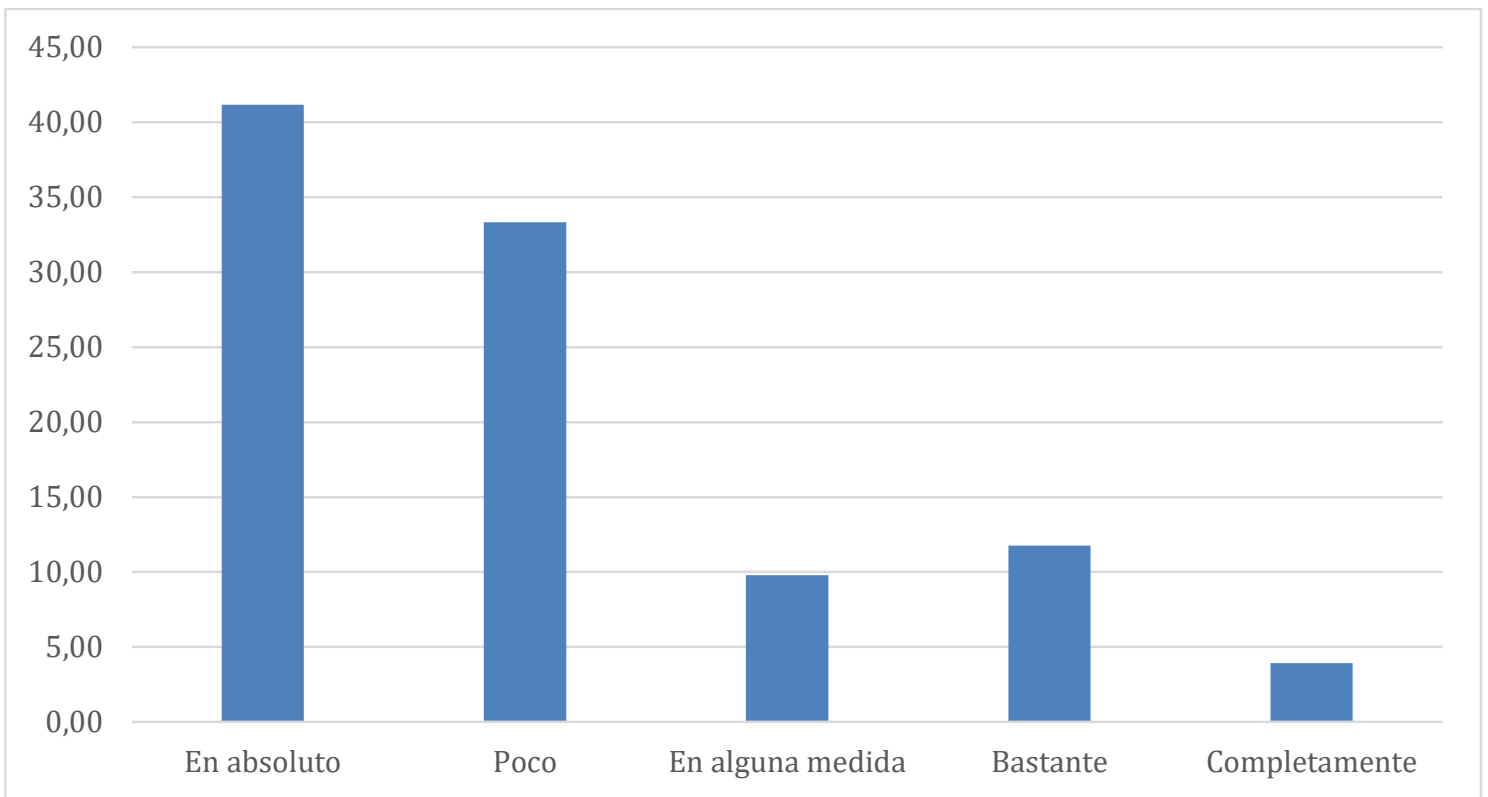

Fuente: elaboración propia

El municipalismo español en el punto de mira de la reforma

Mucho se ha escrito sobre el municipalismo derivado de los procesos descentralizadores iniciados con la Constitución de 1978. Aunque la división administrativa básica no varió sustancialmente con respecto a la etapa anterior, el principio de autonomía local sancionado por la Constitución, junto con las competencias propias otorgadas a las entidades locales, han permitido el desarrollo de una potente administración local durante los últimos 35 años. Este favorable escenario ha permitido que muchas administraciones locales hayan desarrollado su marco de competencias más allá de las asignaciones previstas en la legislación, mediante la adopción de múltiples competencias impropias a lo largo de los años. Este hecho ha permitido a muchos municipios desarrollar estructuras para la provisión de servicios, para la captación de recursos externos no convencionales o para establecer sus propias prioridades, sean estas coincidentes con las demandas de los ciudadanos o no. Lo cierto es que durante todo este tiempo ha prevalecido la premisa de "dejar hacer" a los municipios, ya que la mayoría de sus acciones "impropias" permitían una mejora de la atención a las necesidades y demandas de la ciudadanía, y eran una muestra del proceso madurativo por el que ha transitado la propia sociedad y sus instituciones. Sin 
embargo, la crisis económica y financiera provocada por las malas prácticas desarrolladas desde el sistema financiero han causado, desde 2008, un efecto en cadena con implicaciones en cuanto a la disponibilidad de capital, que se ha visto enormemente restringido $y$, en consecuencia, ha puesto en graves aprietos a todas las personas, empresas y administraciones que funcionaban bajo una lógica de endeudamiento. En el caso español, la socialización del desastre económico provocado por la nefasta gestión de las Cajas de Ahorro ha provocado niveles de endeudamiento nunca vistos, cercanos al $100 \%$ del PIB. La ausencia de una estrategia de reducción de los niveles de endeudamiento externo durante los años de bonanza llevó a incrementos fabulosos de los costes de financiación en los mercados de deuda y, con ello, a una situación límite ante la que hubo que tomar medidas de emergencia que han redundado en importantes reducciones de los presupuestos públicos, principalmente en su dimensión social y territorial. No vamos a detenernos aquí en el modo en que una crisis creada por el sistema financiero acaba siendo costeada por el conjunto de la sociedad, pero es importante no olvidar que precisamente esta ha sido la causa de la orientación al equilibrio presupuestario que han tomado reformas tan necesarias como la LRSAL, cuando podría haberse aprovechado para realizar una auténtica reforma en profundidad de la Ley $7 / 1985$ que diese cumplida respuesta a sus debilidades y carencias, en vez de plantear una reforma "de circunstancias", preocupada principalmente por el equilibrio presupuestario, que puede poner en peligro los costosos avances que se han venido produciendo en el municipalismo español durante los últimos 30 años.

Quizá en relación con estos argumentos podemos encontrar claves para entender las respuestas que dan los encuestados ante la pregunta de qué principios del municipalismo se han visto más debilitados por la entrada en vigor de la LRSAL (ver Figura 14). En el análisis de las respuestas encontramos que los encuestados opinan que el principio más debilitado es la "proximidad de las AAPP al ciudadano" (con más del $30 \%$ de las respuestas), mientras que también se verían muy afectados otros principios como la "descentralización de competencias" (25\%), la eficacia de las medidas tomadas por las AAPP (20\%) o la eficacia de las acciones llevadas a cabo desde las AALL (15\%). Otros principios, en cambio, se verían escasamente debilitados en opinión de los encuestados. Por ejemplo, la gobernabilidad local, incluyendo los procesos participativos, la confianza ciudadana en las capacidades y calidad de los servicios a las AALL o el principio de cooperación administrativa, que incluso puede verse reforzado como consecuencia de la reforma. 
Figura 14. ¿Cuáles de los principios del municipalismo cree que se ven más debilitados por la entrada en vigor de la LRSAL?

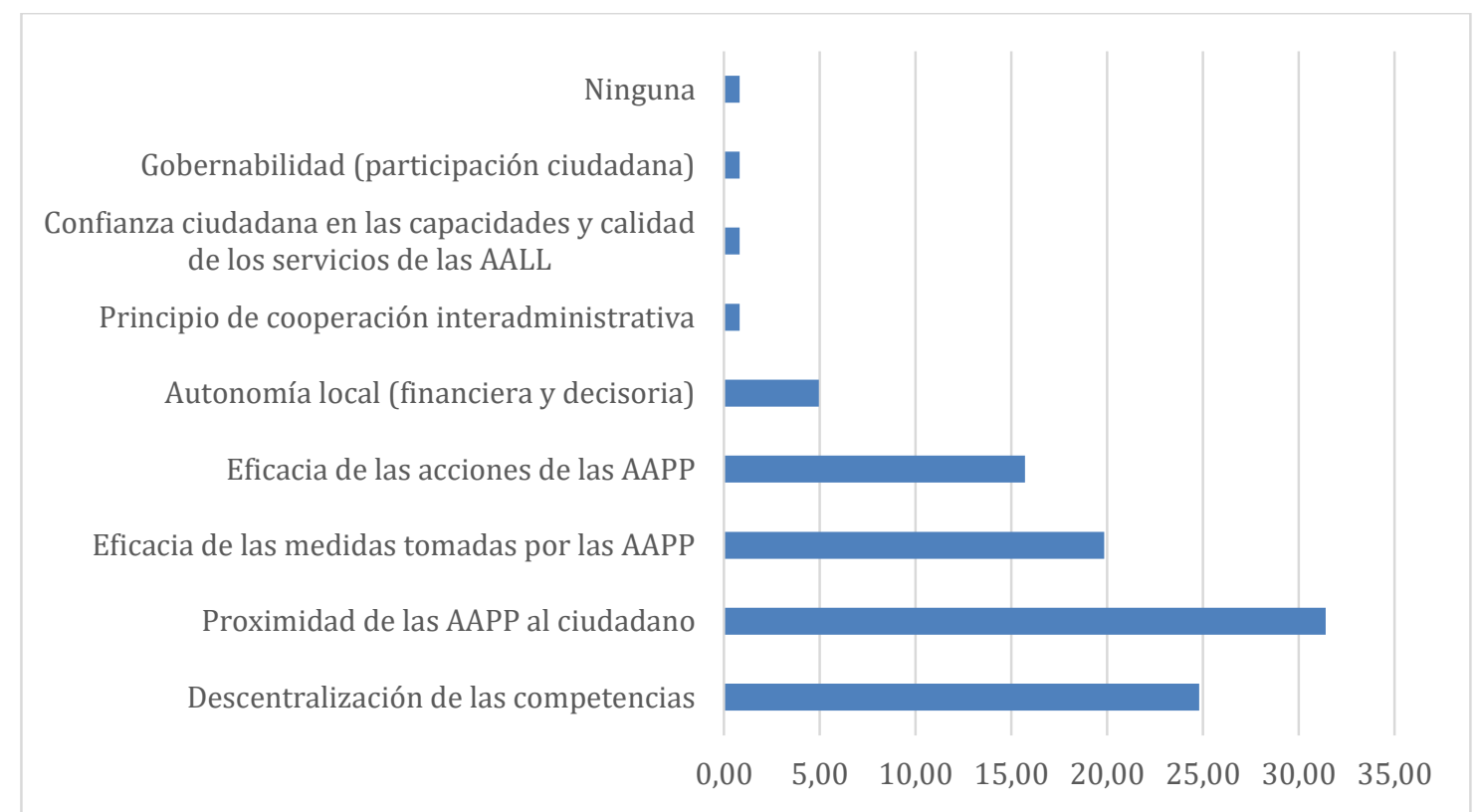

Medidas y soluciones ante los problemas del municipalismo

La encuesta incluye algunas preguntas relacionadas con medidas y soluciones ante los problemas del municipalismo. En este sentido se solicita la opinión sobre las medidas que podrían tomarse para resolver los problemas de excesivo gasto y endeudamiento, desorganización, solapamiento de competencias y duplicidades en el suministro de servicios (ver Figura 15). También se cuestiona sobre las soluciones que pueden tener un mayor impacto en la resolución de las debilidades de la LBRL de 1985 (ver Figura 16).

En cuanto a las primeras, la opinión mayoritaria de la muestra apuesta por dos medidas principales: por un lado, por detectar y reasignar competencias duplicadas en un intento de aproximarse al principio "una competencia, una administración"; por otro lado, la segunda apuesta pasa por la eliminación de las Diputaciones, una medida controvertida que ha estado presente en el debate político en los últimos tiempos. Es llamativo que otras medidas, aparentemente eficaces, obtienen valoraciones mucho más bajas. 
Figura 15. ¿Qué tipo de medidas se podrían tomar para resolver los problemas de excesivo gasto $y$ endeudamiento, desorganización, solapamiento de competencias $y$ duplicidades en suministro de servicios?

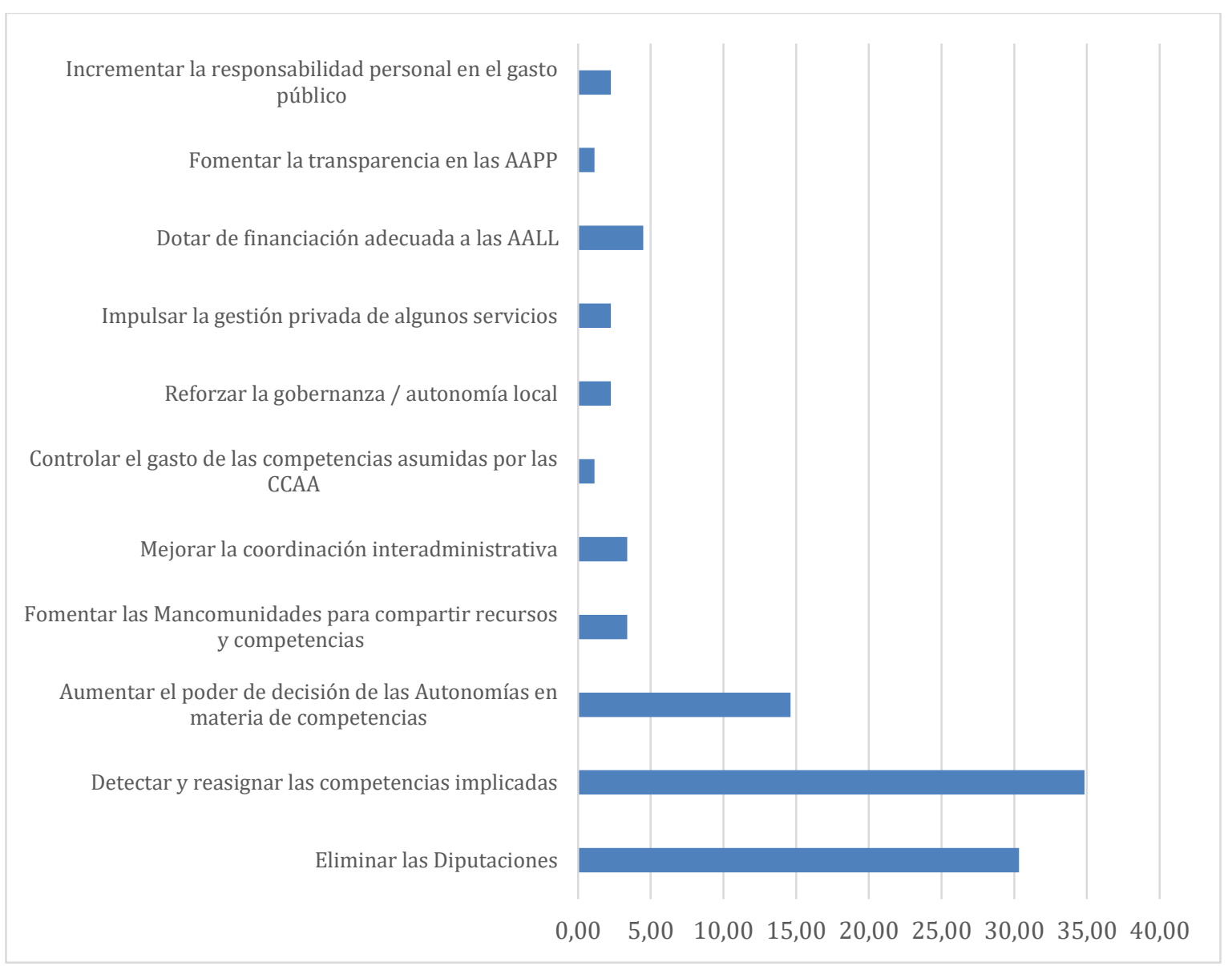

Fuente: elaboración propia

En cuanto a los principios de la Reforma (Figura 16), los encuestados apuestan por priorizar la racionalización de la estructura organizativa de las Administraciones Locales para incrementar la eficacia en su actuación, y acentuar los controles presupuestarios y financieros, en consonancia con el impacto que está teniendo el actual nivel de endeudamiento. 
Figura 16. La LRSAL tiene unos principios concretos. ¿Cuáles de ellos son más útiles para dar respuesta a las debilidades de la LBRL (priorizados de más útil a menos útil)

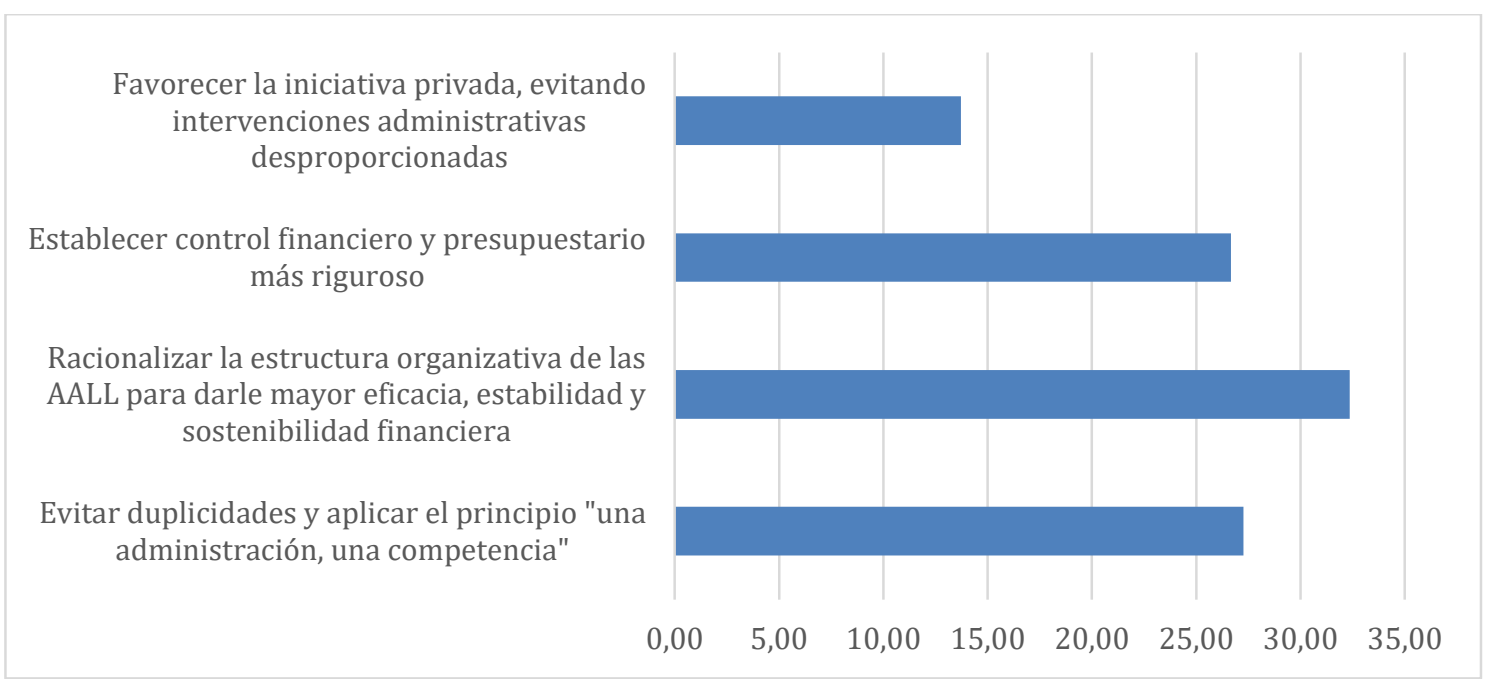

Fuente: elaboración propia

En contraste con las claves de éxito de la reforma, los encuestados destacan los aspectos que no son abordados de manera adecuada (Figura 17). De entre ellos destacan dos: por un lado, las restricciones en las mejoras propuestas por la norma debido a las limitaciones presupuestarias de base; por otro lado, la generalización del reparto de servicios sin que medie el necesario análisis sobre cómo mejorar la proximidad al ciudadano con los recursos disponibles. En un segundo escalón, se incorporan otros aspectos como la no resolución de los conflictos en la asunción de competencias en el caso de servicios prestados, pero no transferidos, la estigmatización de las AALL al obviar el principio de subsidiariedad y proximidad que rige la mayor parte de la reglamentación europea y estatal, o la priorización del equilibrio presupuestario en detrimento de la calidad del servicio al ciudadano.

Uno de los principales retos que afrontan los sucesivos gobiernos es la racionalización en el funcionamiento de la maquinaria administrativa pública y la reducción y control de las duplicidades y multiplicidades en la provisión de servicios y en los procedimientos. Este reto se torna más acuciante, si cabe, en momentos de crisis como el actual, donde los recursos públicos escasean frente a las necesidades de los ciudadanos. A pesar de anteponer como principio fundamental el equilibrio presupuestario, la LRSAL no contribuye sustancialmente, al menos en la opinión de los encuestados, a evitar duplicidades entre AAPP en el suministro de servicios, ni ayuda al ciudadano en el uso de los servicios necesarios (ver Figura 18). Si tenemos en cuenta que la reforma se plantea como un esfuerzo de racionalización y ahorro, las expectativas sobre sus resultados son desalentadoras. 
Figura 17. Indique los principales temas que la LRSAL no aborda de manera adecuada y porqué

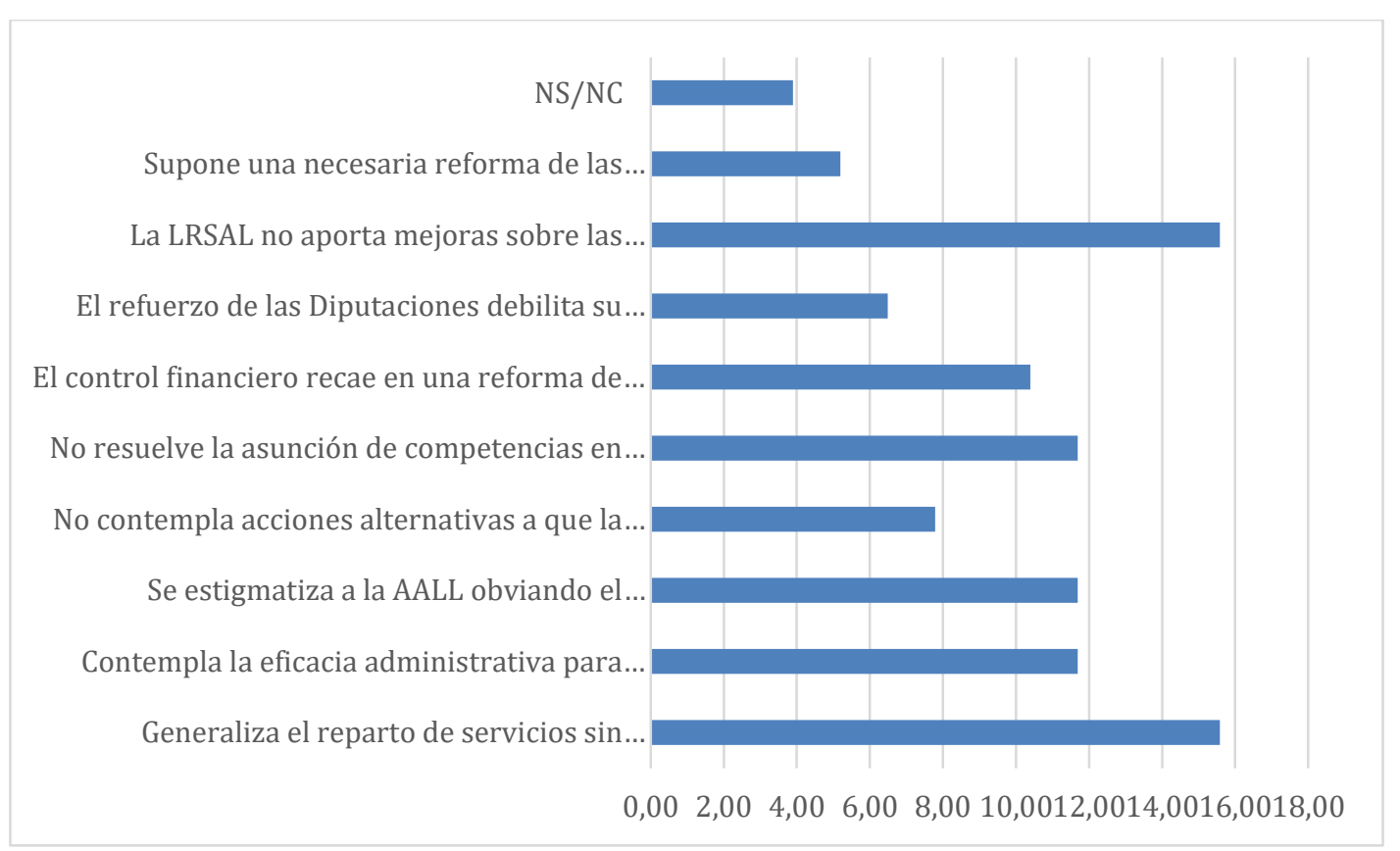

Fuente: elaboración propia

Figura 18. ¿Cree que la LRSAL ayuda a evitar duplicidades entre AAPP en el suministro de servicios, y ayuda al ciudadano en el uso de los servicios necesarios?

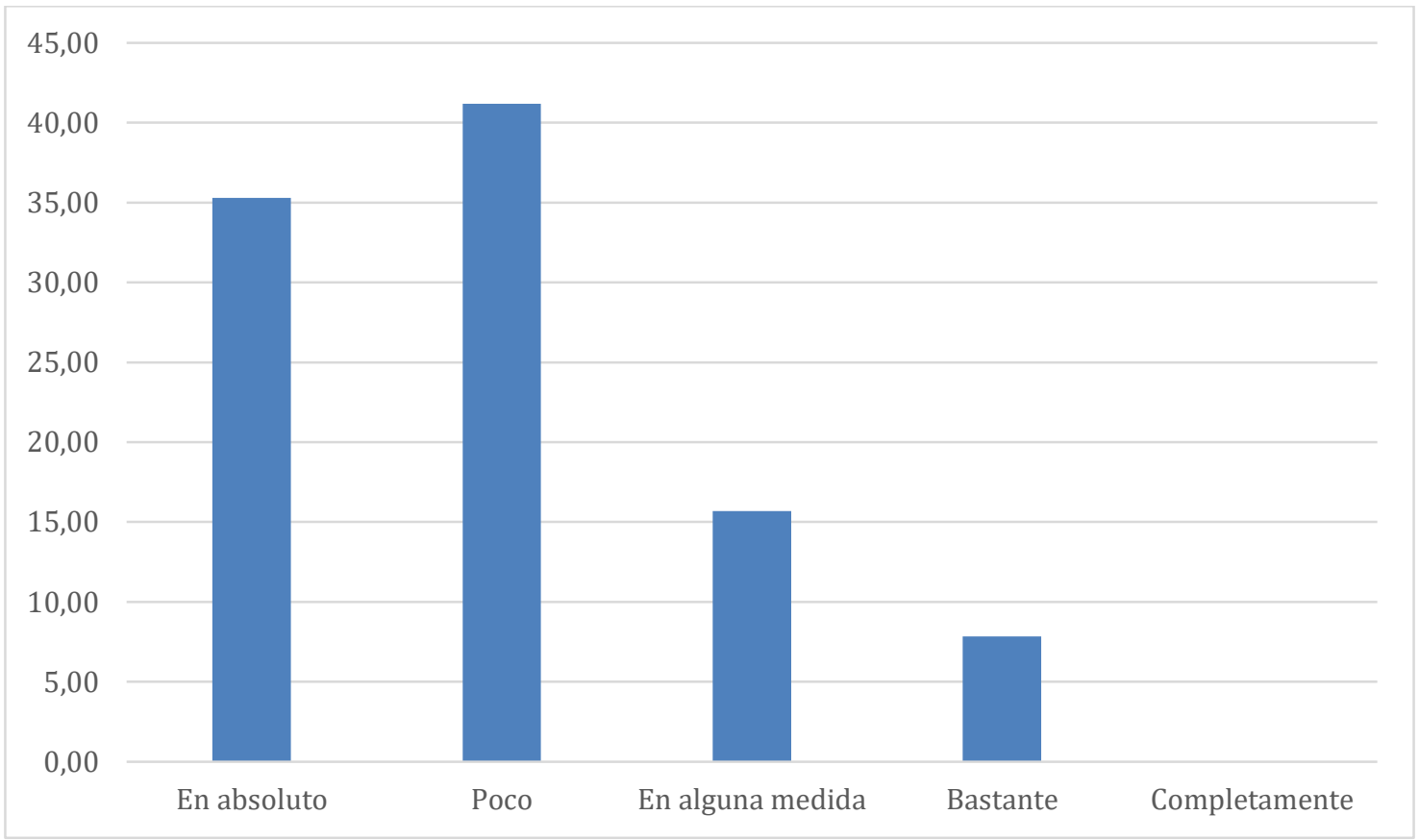

Fuente: elaboración propia 
Los principios de sostenibilidad económica y equilibrio presupuestario que rigen la norma tropiezan con la realidad territorial y social. Con frecuencia, los servicios públicos locales no atienden prioritariamente a parámetros de ahorro económico sino, como su propio nombre indica, de servicio público, lo cual significa necesariamente que habrá ocasiones en las que un servicio asuma déficits en aras de la cobertura de una necesidad social considerada primaria o irrenunciable. Sin embargo, la LRSAL impone como principio que los municipios solo podrán ejercer competencias impropias o atribuidas por delegación cuando no se ponga en riesgo la estabilidad financiera y cuando no se incurra en duplicidades. Sobre el papel, esta disposición puede parecer sensata y adecuada. Sin embargo, la realidad socioeconómica local es mucho más compleja, y presenta múltiples aristas y excepcionalidades que bien pueden contradecir esta afirmación. En el caso de la asunción de competencias impropias, es lógico pensar que son competencias que alguna otra administración prestará en un municipio concreto de forma más o menos eficiente, de modo que el servicio público quede cubierto. Pero esta suposición no siempre se cumple y, como resultado, se generan situaciones de desigualdad o carencia que afectan a los ciudadanos y reducen su calidad de vida.

Figura 20. La LRSAL impone que los municipios puedan ejercer competencias impropias o atribuidas por delegación solo cuando no se ponga en riesgo la estabilidad financiera y cuando no se incurra en duplicidades. ¿Cómo considera esta disposición?

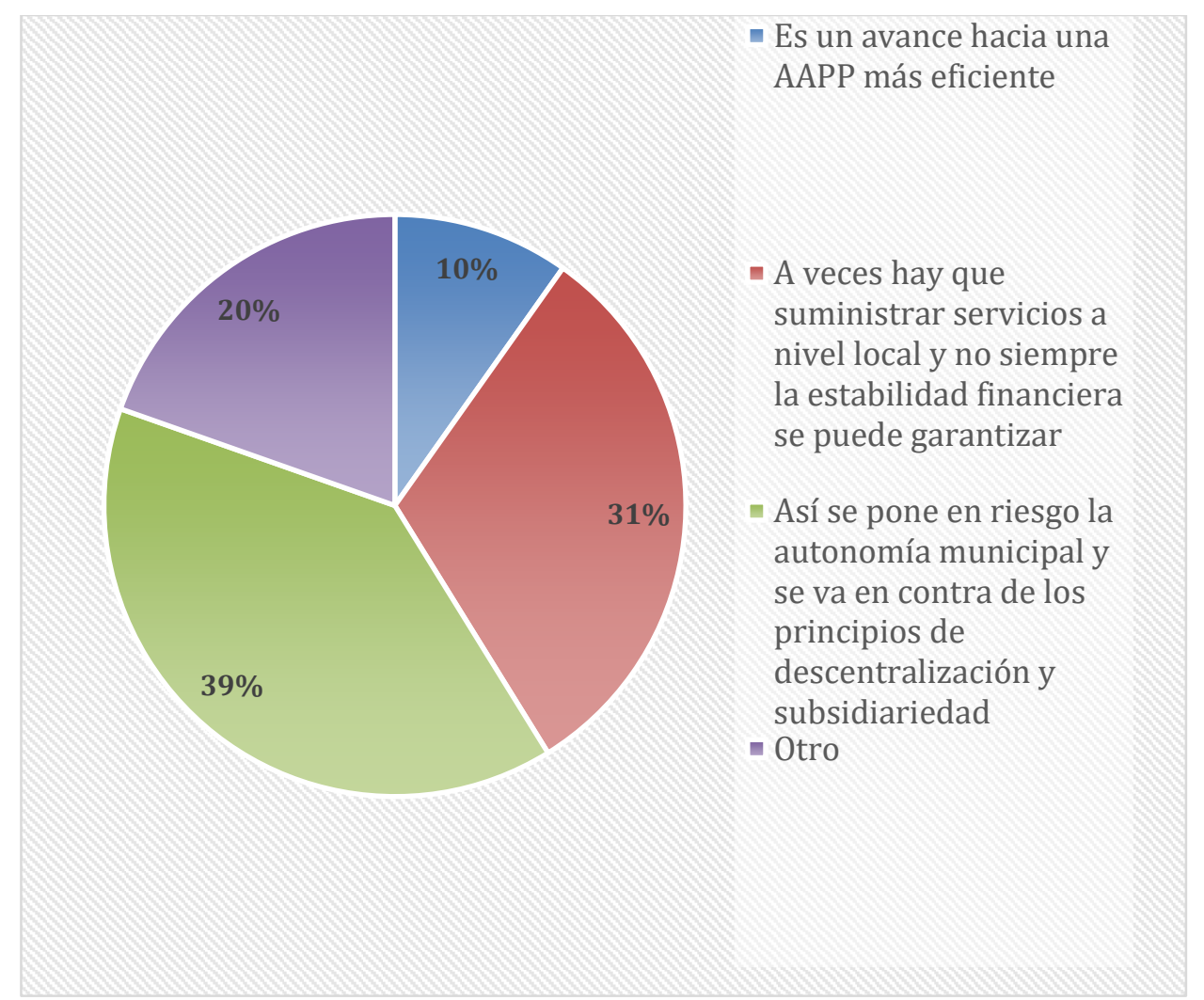

Fuente: elaboración propia 
Imaginemos una ciudad media que es centro turístico y de servicios. El turismo es estacional y el comercio ha liberalizado los horarios de forma que predomina el trabajo por turnos y/o en fines de semana. El mercado de trabajo está dominado por empleos de baja cualificación y elevada precariedad laboral. La mayoría de las familias no puede afrontar las cuotas estándar de las escuelas infantiles privadas. Se trata de un segmento de edad ( 0 a 3 años) que no queda cubierto por la educación obligatoria, por lo que las familias con empleos inestables, de horarios variables o intermitentes, entre otras, se ven en la obligación de acudir a guarderías privadas. La situación está afectando la calidad de vida de una parte relevante de la sociedad local. El gobierno municipal decide poner en marcha un acuerdo con las escuelas infantiles privadas para incorporar un número determinado de plazas subvencionadas. La medida permite a muchas familias mayor flexibilidad para afrontar las demandas del mercado de trabajo, lo que redunda en una mejora de sus oportunidades y, por extensión, de la economía local. $Y$, sin embargo, el gobierno local ha ejercido una competencia impropia que no le corresponde y que, de acuerdo con la LRSAL, no debería ejercer en ningún caso, a no ser que exista una delegación expresa de la administración competente, o que no se comprometa el equilibrio presupuestario. Este problema afecta a un amplio conjunto de necesidades que se manifiestan en la escala local, pero de las que las AALL no son competentes (comedores escolares, asistencia a domicilio, transporte público, etc.), y que no están siendo adecuadamente cubiertas por quienes deberían ejercerlas.

\section{Conclusiones}

El trabajo realizado nos ha permitido adquirir un conocimiento profundo tanto del contenido de la herramienta normativa como de las implicaciones de la reforma que propone la LRSAL. La de 2013 es la última y más amplia de las reformas realizadas a la Ley de Bases de Régimen Local de 1985 y tiene profundas implicaciones en la forma de operar de las administraciones locales en un contexto en el que estos niveles de gobierno se han convertido, en la práctica, en verdaderos garantes de algunos de los principales derechos reconocidos por la constitución.

Tanto el análisis de los contenidos de la reforma como el sentido de las respuestas de los encuestados nos permiten corroborar la primera de las hipótesis planteadas que afirma que la LRSAL responde a un modelo clásico de burocracia que fomenta una intervención estatal en detrimento de la autogestión local/municipal. Se trata de una reforma que parte de una doctrina eminentemente centralizadora que no se corresponde bien con la naturaleza autónoma de los municipios a lo largo de la historia española. A pesar de esta valoración negativa, la Ley contiene una aspiración positiva, pero, a juicio de los autores, mal desarrollada con respecto a la realidad de las administraciones locales. Su revisión en las disposiciones relativas al estatuto jurídico de la Administración Local es interesante cuando trata de evitar las duplicidades con las competencias. Pero, aunque trate de estabilizar los presupuestos y lograr una mejor eficiencia de los recursos públicos, no tiene en cuenta las necesidades de los municipios de proveer a sus ciudadanos los bienes y servicios que, desde un gobierno más centralizado, resultan menos eficaces.

La segunda hipótesis que nos hemos planteado en este trabajo afirma que la LRSAL es 
una ley de racionalización del gasto público y no tanto de sostenibilidad. De acuerdo con los análisis realizados podemos confirmar también esta hipótesis. La Carta Europea de Autonomía local permite un gobierno no solo como ente gestor sino repolitizado, e impulsa la acción ciudadana a través de lo local. Es decir, fomenta una mayor diversidad local y libertad para cada municipio a la hora de decidir sus propias necesidades competenciales. Una filosofía que choca con el proyecto presentado en 2013 que propone una actuación más centralizada con el fin de evitar asimetrías y el sobredimensionamiento en materia de Hacienda Local. Es decir, existe una clara apuesta por un modelo clásico de burocracia. Este proyecto se sustenta en la exigencia de cumplir el artículo 135 CE sobre estabilidad presupuestaria en el marco de las medidas de contención del gasto público. Sin embargo, esta orientación provoca que se actúe, en este caso, en contra de los artículos 140 a 142 CE referentes a la autonomía, la suficiencia y la legitimidad directa de cada entidad local, tanto por los mecanismos de control propuestos como por el incremento de funciones atribuidas a las Diputaciones provinciales como órganos directivos de la gestión de los municipios.

Por último, se cumple la tercera de las hipótesis de partida cuyo enunciado indica que "Ia LRSAL se apropia, mediante su reglamento, de las potestades constitucionales de las entidades locales referidas en los artículos 137, 140 a 142". Con el ánimo de fomentar una mayor actuación municipal en el interés del ciudadano, y una regulación del presupuesto público mejor y más controlada, para alcanzar los objetivos de su gobierno en pos de la satisfacción del municipio, es apropiado decir que se trata de obtener una mejor formulación de la regulación instrumental de la normativa local para un mayor desarrollo de los servicios mínimos y extraordinarios esperados. En este sentido, el artículo 25.1 y 28 de la LRBRL actúa como freno a causa de sus deficiencias de regulación en cuanto a las potestades municipales, al tiempo que la Reforma 27/2013 de 27 de diciembre no mejora, sino que corrige hacía la intervención estatal en lo local cuando dice que: "el Gobierno -central- fijará normas sobre los procedimientos de control, metodología de aplicación, criterios de actuación, derecho y deberes en el desarrollo funciones públicas necesarias para las corporaciones locales" (LRSAL). Es cierto que se consigue una simplificación de la organización, pero se obtiene a costa del autogobierno local y la participación ciudadana en lo propio, al desarrollar unas competencias bajas y una carga lesiva que convierte los gobiernos municipales en meros apoyos administrativos de legisladores que proponen soluciones genéricas no derivadas de las necesidades reales de cada municipio, sea este pesquero, industrial o exportador de plátanos, por poner algunos ejemplos de la enorme diversidad local.

En conclusión, podemos afirmar que la LRSAL constituye una reforma de marcado carácter ideológico que, mediante la utilización de los principios de equilibrio presupuestario, avanza hacia un proceso de re-centralización administrativa y de vaciamiento de la acción municipal. El modelo de funcionamiento que se propone conllevará, a buen seguro, numerosos problemas y conflictos en la provisión de servicios públicos y en la calidad de vida percibida por los ciudadanos. 


\section{Bibliografía}

CUENCA CERVERA, J. (2010) Manual de Dirección y Gestión de Recursos Humanos en los Gobiernos Locales, INEP. 2010, 258 pag. ISBN 9788473512923.

Ley $7 / 1985$, de 2 de abril, Reguladora de las Bases del Régimen Local

SUÁREZ PANDIELLO, J. (2014) "De crisis, perspectivas y Haciendas locales", en Revista Democracia y Gobierno Local, Número 24, Primer trimestre 2014

PAGÉS I GALTÉS, J. (2014) "La reforma de la Hacienda local a la luz de los principios de autonomía y suficiencia financiera", en Revista Democracia y Gobierno Local, Número 24 Primer trimestre 2014

OLMEDA, J. (2012) "Los gobiernos locales", en Manual de 'Las Administraciones Públicas en España'. Editorial Tirant lo Blanc. Valencia.

Comisión para la Gobernanza Global de la ONU (2005) Libro Blanco sobre la Gobernanza. 